\title{
Background Paper on Global Trends in Food Production, Intake and Composition
}

\author{
Petro Wolmarans \\ Nutritional Intervention Research Unit, Medical Research Council, Cape Town, South Africa
}

\section{Production of Vegetable Oils and Animal Sources of Fat}

\section{Introduction}

Vegetable oils and animal fats are the main sources of fat in the human diet. Another source of fat in the diet is nuts, while cereals and legumes also contain small amounts of fat. A food item that is normally not a source of fat can become high in fat as a result of the use of oils and fats in food preparation. As an example, a boiled potato which contains less than $1 \%$ fat becomes an important source of fat when French fries (about 7\% of fat) or potato crisps (about 35\% of fat) are prepared. Confectionery and fast foods are important sources of fat in the diet as vegetable oils or animal fats are often one of the main ingredients of these food items. The fat in food consists of different amounts of saturated (SFA), monounsaturated (MUFA) and polyunsaturated (PUFA) fatty acids. As a result of the partial hydrogenation of vegetable oils, trans fatty acid-containing vegetable fats are produced. When these vegetable fats are used in the preparation of processed foods and confectionery, the food items will contain trans fatty acids. Most vegetable oils are high in PUFA or MUFA, while fat from animal sources is generally regarded as an important source of SFA. The main dietary source of the long-chain PUFAs (LCPUFAs), eicosapentaenoic acid (EPA; C20:5n-3) and docosahexaenoic acid (DHA; C22:6n-6), is fish - especially fatty fish.

\section{KARGER}

Fax +41613061234 E-Mail karger@karger.ch www.karger.com
(C) 2009 S. Karger AG, Basel and FAO

0250-6807/09/0553-0244\$26.00/0

Accessible online at:

www.karger.com/anm
Trends in the production of food sources of fat have a global impact on the availability of fat for human consumption. Global data on fat supply obtained from food balance sheets (FBS) as well as individual food intake data contribute to an understanding of the relationship between fat intake patterns and health outcomes. In order to translate food intake data into fatty acids consumed, information from food composition databases is required. Information from food composition databases on the fatty acid composition of foods also helps monitor changes and trends.

\section{Data Generation from FBS}

FBS compiled by the Food and Agriculture Organization (FAO) of the United Nations provides information on the production of food commodities [FAOSTAT/FBS, 2006]. Data last updated in 2006 were made available by AGNA/FAO on computer disk, and this dataset provides production data until the year 2003 [FAOSTAT/FBS, 2006]. The mean of 3 years was calculated for the presentation of data, e.g. the value for 2001-2003 represents the mean value for the years 2001, 2002 and 2003 (details of the categorization of countries are given in the 'Appendix'). Production at the household level is not taken into account with the compilation of the FAO FBS, but supply data at the national level are used. Therefore, the production figures could be an underestimation of the actual pro-

Tel. +27 21938 0268, Fax +27 21938 0321, E-Mail petro.wolmarans@mrc.ac.za 


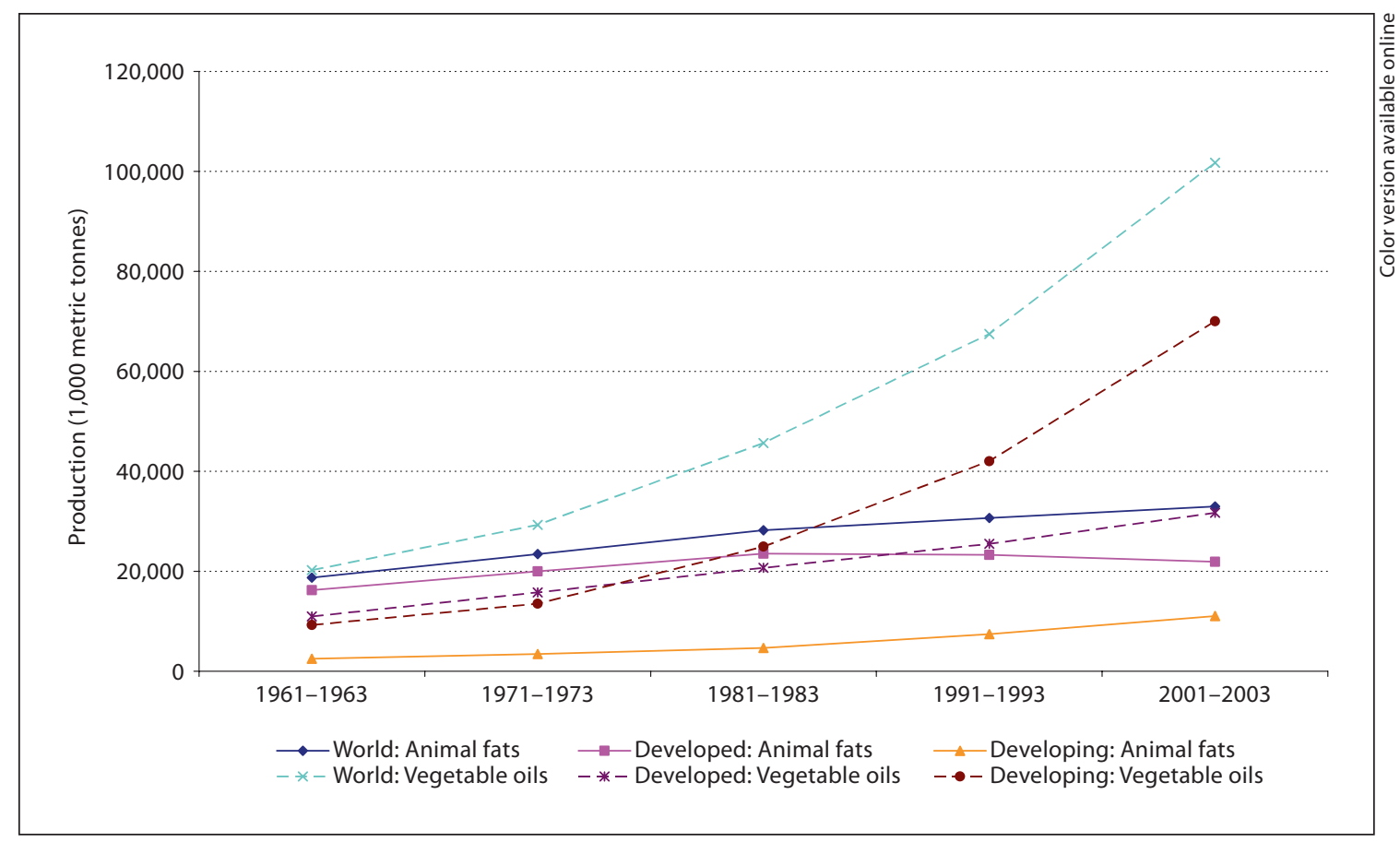

Fig. 1. Trends in the production (domestic supply) of vegetable oils and animal fats, globally as well as in developed and developing countries [FAOSTAT/FBS, 2006].

duction of the vegetable oils and animal fat sources, which should be taken into account when interpreting the data.

\section{Production of Vegetable Oils}

Production Statistics

The global production (domestic supply) of vegetable oils increased significantly between 1961-1963 and 20012003, especially in developing countries (fig. 1).

Global trends in the production of specific vegetable oils between 1995-1997 and 2001-2003 are shown in table 1 . Soybean oil and palm oil are the major vegetable oils produced globally. The production of most of the oils, with the exception of sunflower oil, increased between 1995-1997 and 2001-2003 [FAOSTAT/FBS, 2006]. During 2001-2003, the world production of vegetable oils increased by $25.9 \%$. At the same time the production of palm oil increased by $51.3 \%$ and of soybean oil by $42.8 \%$ (table 1).

Developing countries produced $68.8 \%$ and developed countries $31.2 \%$ of the total amount of vegetable oil during the period 2001-2003 (table 2). Soybean oil was the main vegetable oil produced in developed countries, while palm oil was the main vegetable oil produced in developing countries (table 2).

Trends in Food Production, Intake and Composition
Asia is the main producer of palm oil, rape and mustard oil, groundnut oil, coconut oil, cottonseed oil and palm kernel oil, while South America is the main producer of soybean oil. Europe is the main producer of sunflower oil and olive oil (table 3). All the vegetable oils are, however, produced in varying amounts in the different regions of the world (table 3). Oceania is not a major vegetable oil producing region.

Soybean Oil. South America was the main soybean oil-producing region in the world in 2001-2003 (table 3). In South America, Brazil (52.1\%) and Argentina (42.1\%) were the main producers of soybean oil during this period [calculated from FAOSTAT/FBS, 2006]. North and Central America are also main producers of soybean oil, and the United States produced $92.2 \%$ of the soybean oil in this region in 2001-2003. In addition to being the main producer of soybean oil $(4,250,133$ metric tonnes, MT; $61.6 \%$ of total) in Asia (2001-2003), China was also the main importer (1,231,998 MT; 26.5\%) of this commodity [FAOSTAT/FBS, 2006]. Another important soybean-producing region of the world is Europe, where the European Union was responsible for the production of $91.7 \%$ of the soybean oil in this region in 2001-2003 [calculated from FAOSTAT/FBS, 2006].

Ann Nutr Metab 2009;55:244-272 
Table 1. Global trends in the production (domestic supply) of vegetable oils in 1995-1997, 1998-2000 and 2001-2003

\begin{tabular}{lrrrr}
\hline & $1995-1997$ & $1998-2000$ & $2001-2003$ & Increase $^{1}, \%$ \\
\hline All vegetable oils & 80,777 & 91,120 & 101,722 & 25.9 \\
$\quad$ Soybean & 20,108 & 24,531 & 28,722 & 42.8 \\
Palm & 17,069 & 20,295 & 25,819 & 51.3 \\
Rape and & & & & \\
mustard & 11,147 & 12,664 & 12,353 & 10.8 \\
Sunflower & 9,099 & 9,533 & 8,612 & -5.4 \\
Groundnut & 4,885 & 4,975 & 5,353 & 9.6 \\
Cottonseed & 3,817 & 3,718 & 3,824 & 0.2 \\
Coconut & 3,357 & 3,186 & 3,416 & 1.8 \\
Olive & 2,477 & 2,659 & 3,024 & 22.1 \\
Palm kernel & 2,232 & 2,586 & 3,215 & 44.0 \\
Sesame seed & 713 & 726 & 827 & 16.0 \\
\hline
\end{tabular}

Data presented in 1,000 metric tonnes, with values representing the means of each 3-year period [FAOSTAT/FBS, 2006].

${ }^{1}$ Difference between the periods 1995-1997 and 2001-2003.
Table 3. Vegetable oils produced in different regions of the world (2001-2003)

\begin{tabular}{lrrrrrr}
\hline & Asia & Africa & Europe & America $^{1}$ & America $^{2}$ & Oceania \\
\hline Soybean & 6,902 & 176 & 3,279 & 8,925 & 9,433 & 7 \\
Palm & 22,231 & 1,858 & 0 & 422 & 984 & 324 \\
Rape and & & & & & & \\
$\quad$ mustard & 6,130 & 15 & 4,394 & 1,638 & 30 & 145 \\
Sunflower & 1,534 & 360 & 4,920 & 281 & 1,491 & 25 \\
Groundnut & 3,777 & 1,296 & 78 & 118 & 83 & 2 \\
Cottonseed & 2,643 & 338 & 123 & 411 & 265 & 44 \\
Coconut & 3,050 & 107 & 35 & 141 & 16 & 68 \\
Olive & 326 & 229 & 2,457 & 2 & 11 & 0 \\
Palm kernel & 2,556 & 421 & 0 & 59 & 154 & 25 \\
\hline
\end{tabular}

Data presented in 1,000 metric tonnes, with values representing the means of each 3-year period [FAOSTAT/FBS, 2006].

${ }^{1}$ North and Central America.

${ }^{2}$ South America.
Table 2. Production (domestic supply) of vegetable oils in developed and developing countries between 1995-1997 and 2001-2003

\begin{tabular}{lrrrr}
\hline & $1995-$ & $1998-$ & $\begin{array}{l}2001- \\
\text { Increase }\end{array}$ \\
& 1997 & 2000 & 2003 & \multicolumn{1}{l}{$\%$} \\
\hline Developed countries & & & & \\
Total vegetable oil & 28,425 & 31,331 & 31,714 & 11.6 \\
$\quad$ Soybean & 10,901 & 12,402 & 12,716 & 16.6 \\
Rape and mustard & 5,936 & 6,986 & 6,730 & 13.4 \\
Sunflower & 5,375 & 5,594 & 5,588 & 4.0 \\
Olive & 1,946 & 2,008 & 2,464 & 26.6 \\
Cottonseed & 1,153 & 1,057 & 945 & -18.0 \\
Groundnut & 227 & 160 & 198 & -12.8 \\
Sesame seed & 62 & 67 & 71 & 14.5 \\
Coconut & 109 & 110 & 45 & -58.7 \\
\hline Developing countries & & & & \\
Total vegetable oil & 52,352 & 59,789 & 70,008 & 33.7 \\
Palm & 17,069 & 20,295 & 25,819 & 51.3 \\
Soybean & 9,207 & 12,129 & 16,006 & 73.9 \\
Rape and mustard & 5,211 & 5,678 & 5,622 & 7.9 \\
Groundnut & 4,659 & 4,815 & 5,156 & 10.7 \\
Sunflower & 3,725 & 3,938 & 3,023 & -18.8 \\
Coconut & 3,248 & 3,076 & 3,371 & -3.8 \\
Cottonseed & 2,664 & 2,661 & 2,879 & 8.1 \\
Palm kernel & 2,229 & 2,586 & 3,214 & 44.2 \\
Sesame seed & 651 & 660 & 756 & 16.1 \\
Olive & 531 & 651 & 560 & 5.5 \\
\hline
\end{tabular}

Data presented in 1,000 metric tonnes, with values representing the means of each 3-year period [FAOSTAT/FBS, 2006].

${ }^{1}$ Difference between the periods 1995-1997 and 2001-2003.
Palm Oil. Palm trees are grown successfully in tropical regions of the world within $20^{\circ}$ of the equator. Asia was the main palm oil-producing region in the world during the period 2001-2003 (table 3). The major palm oil-producing countries in 2007 were Indonesia (44\%), Malaysia (41.5\%), Thailand (2.7\%), Nigeria (2.2\%) and Columbia (2\%) [Global Oils \& Fats Business Magazine, 2008].

In 2007, large amounts of palm oil were exported from Malaysia to China (3,840,380 tonnes), the European Union (2,063,226 tonnes) and Pakistan (1,070,067 tonnes) [Global Oils \& Fats Business Magazine, 2008]. A marked increase in the export of palm oil to countries such as Iran, China, the United States, Vietnam, the European Union and South Africa was observed between 2000 and 2007 [Global Oils \& Fats Business Magazine, 2008]. In contrast, major decreases in the export of palm oil from Malaysia to Jordan, Saudi Arabia and Egypt were observed [Global Oils \& Fats Business Magazine, 2008].

Sunflower Oil. The world production of sunflower oil decreased between 1995-1997 and 2001-2003 (table 1). Europe, Asia and South America were the main producers of sunflower oil during this period (table 3). Africa is not a main producer of sunflower oil, but South Africa produces $84.6 \%$ of the sunflower oil produced in this region [FAOSTAT/FBS, 2006]. In addition to standard sunflower oil, high in linoleic acid (LA), mid-oleic and higholeic sunflower oils are now also available (see 'Fats and Fatty Acid Composition in the Food Supply'). 
Rape and Mustard Oil. An increase of about 11\% in the production of rape and mustard oil was observed between 1995-1997 and 2001-2003 (table 1). The main rape and mustard oil-producing areas of the world are Asia, Europe, and North and Central America (table 3).

Canola oil, one of the cultivars of rapeseed oil, was developed in Canada in the early 1970s using traditional plant breeding techniques [Canola Council of Canada, 2008]. The aim was to remove the anti-nutrient components erucic acid and glucosinolates to make the oil safe for human consumption. Canada is an important producer of canola/rapeseed, and is responsible for $20 \%$ of the world's production of this commodity [Canola Council of Canada, 2007].

Olive Oil. The world production of olive oil increased by $22.1 \%$ between 1995-1997 and 2001-2003 (table 1). Europe is the main olive oil-producing area of the world (table 3) with Spain (53.2\%), Italy (25.7\%) and Greece $(19.2 \%)$ being the main producers in this region during the period 2001-2003 [FAOSTAT/FBS, 2006]. Spain produced 1,306,167 MT, Italy 630,567 MT, Greece 472,646 MT and Portugal 37,407 MT during the period 20012003. France produced only $3,833 \mathrm{MT}$ during this time, but imported 98,306 MT. In addition to its high production of olive oil, Italy also imported 528,843 MT during the period 2001-2003. One of the characteristics of the diet in Mediterranean countries is the liberal consumption of olive oil as part of the diet [Nestle, 1995]. This explains the trend in the production and import of olive oil into these countries.

Factors Influencing the Production of Vegetable Oils

Examples of factors that influence the production of vegetable oils are population expansion and the per capita consumption of vegetable oils [Broeska, 2007]. It is estimated that the world population will grow to 7 billion people by the year 2013 compared to 6 billion in the year 1999 [US Census Bureau, 2004], and this population growth will impact on food demand.

Globalization can contribute to an increase in the availability and consumption of vegetable oil [Hawkes, 2006]. New government policies in Brazil, in connection with the production and export of soybean oil, have, for example, contributed to an increase in the availability of soybean oil in countries such as China and India [Hawkes, 2006].

Changes in food consumption patterns will also influence the production of vegetable oils. As the demand for vegetable oils grows, more land will be required for the production of oil seeds. Gerbens-Leenes and Nonhebel
[2002] used a model to determine the total land requirements for a specific food, based on the type and amounts consumed, and it was shown that for vegetable oil $20.7 \mathrm{~m}^{2}$ year $\mathrm{kg}^{-1}$ land is required, while for margarine this figure is $21.5 \mathrm{~m}^{2}$ year kg-1.

Irregular and unstable weather conditions and inadequate supply of raw material can impact on the production of oil seeds [Export Processing Zones Authority, 2005].

Although there was a decrease in the area planted with oil seeds, between 2005 and 2007 vegetable oil production increased by $7 \%$ as a result of a global increase in oil seed yields and the growth in palm oil production [OECD-FAO, 2008].

Vegetable oil prices are high and have doubled or tripled since the beginning of 2007 [Patton, 2008]. Reasons given for the increase in prices are ascribed to a drop in production due to weather conditions and also bans on the export of oils by some governments to protect the domestic food prices (Patton, 2008). Vegetable oil prices will be influenced by an increase in the demand for vegetable oils from countries such as China and India [Patton, 2008].

The use of vegetable oils for the production of biofuels also influences the price of vegetable oils. There are indications that about half of the increased demand for grains and vegetable oils between 2005 and 2007 was due to biofuels [OECD-FAO, 2008]. It is also forecasted that between 2005 and 2017, the use of vegetable oils for biofuels will increase and will account for more than a third of the expected growth in need [OECD-FAO, 2008]. It is estimated that there will be a 29-million-tonne increase in the production of major oils between 2005 and 2010, and that 16 million tonnes of this will be for fuel [Canola Council of Canada, 2007]. The price of vegetable oil is influenced by the demand for the production of biofuel, and markets for vegetable oil move in tandem with crude oil prices [Thoenes, 2006; Business Standard, 2009].

\section{Production of Animal Source Fat}

Production Statistics

Milk and milk products as well as livestock are the most important sources of animal fat in the diet.

Milk Production. Milk production (excluding butter) increased in both developed and developing countries between 1962-1964 and 2001-2003, but the increase was larger in developing countries (fig. 2). The processing of milk (excluding butter) was, however, higher in developed countries than in developing countries. Cheese is an important commodity in developed countries, and in 2001-2003, the production in these countries was about 


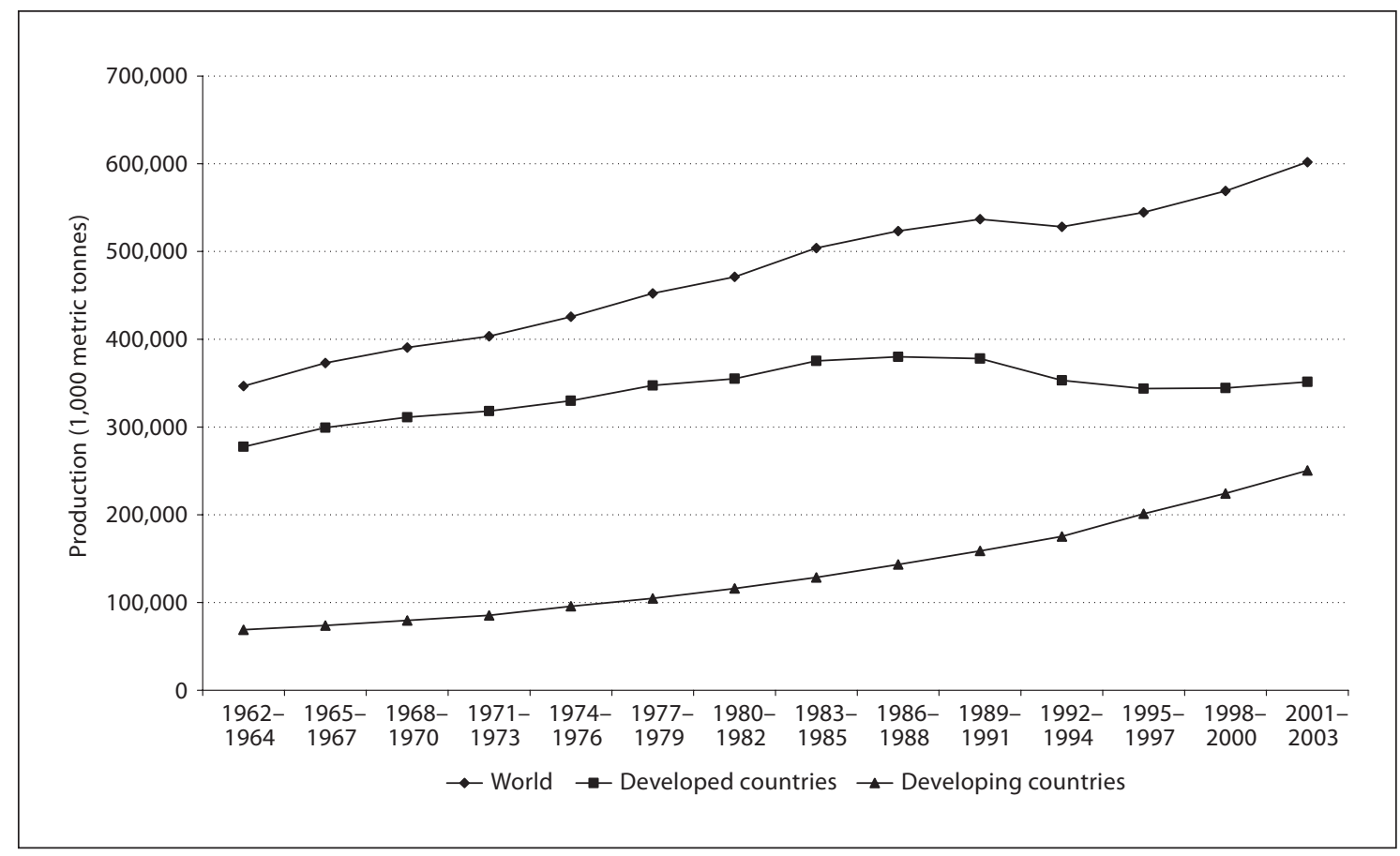

Fig. 2. Production (domestic supply) of milk (excluding butter) globally as well as in developed and developing countries [FAOSTAT/FBS, 2006].

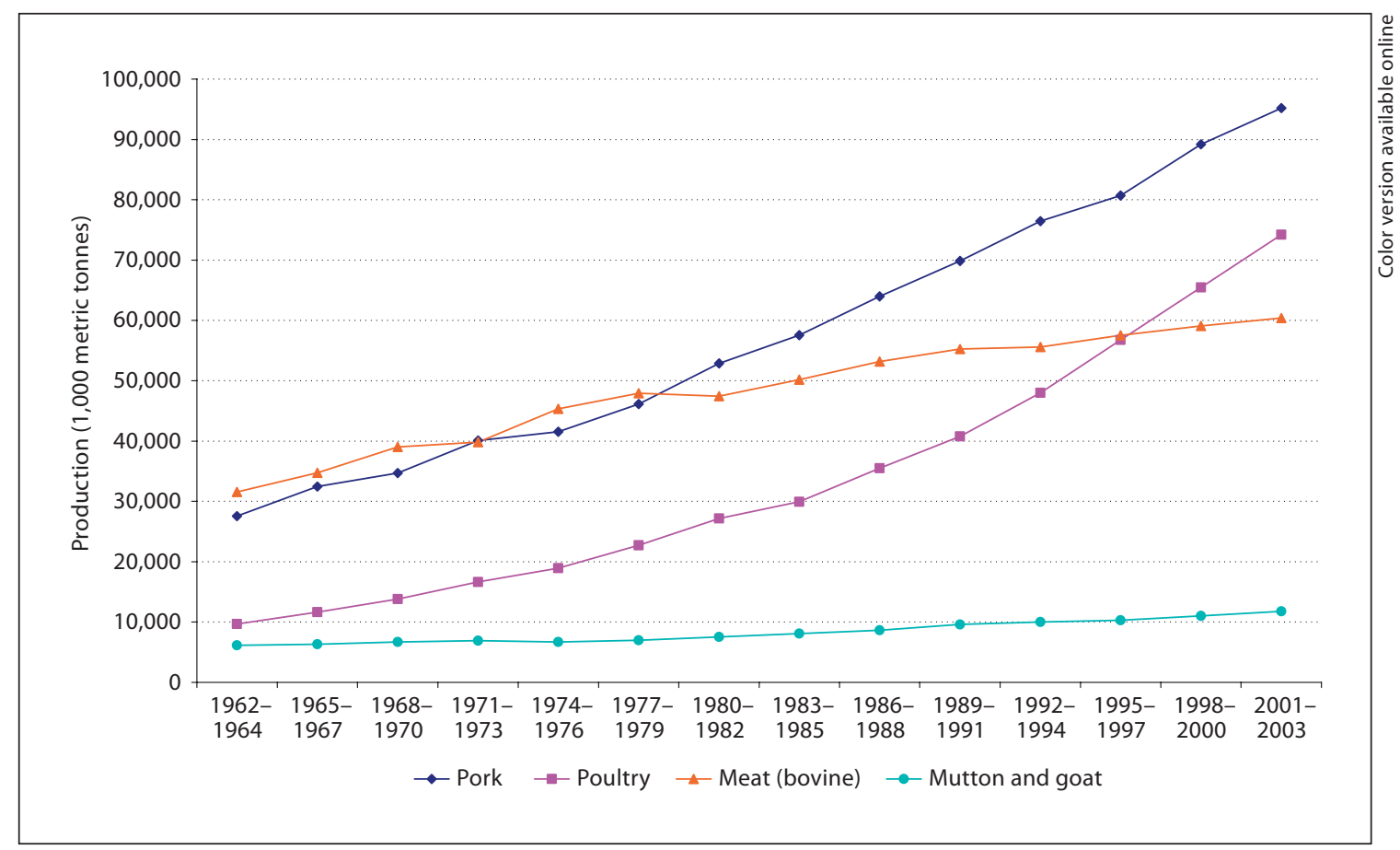

Fig. 3. Global production (domestic supply) of beef, pork, poultry, and mutton and goat [FAOSTAT/FBS, 2006]. 
Table 4. Trends in the production of animal source foods

\begin{tabular}{|c|c|c|c|c|c|c|c|}
\hline & $\begin{array}{l}\text { Milk } \\
\text { (exc. butter) }\end{array}$ & Cheese & $\begin{array}{l}\text { Meat } \\
\text { (bovine) }\end{array}$ & $\begin{array}{l}\text { Mutton } \\
\text { and goat }\end{array}$ & Pork & Poultry & Eggs \\
\hline \multicolumn{8}{|l|}{ World } \\
\hline 1995-1997 & 544,629 & 14,881 & 57,514 & 10,303 & 80,713 & 56,785 & 48,934 \\
\hline $1998-2000$ & 568,918 & 15,972 & 59,072 & 11,000 & 89,183 & 65,480 & 53,759 \\
\hline 2001-2003 & 601,879 & 17,212 & 60,404 & 11,761 & 95,214 & 74,200 & 59,521 \\
\hline \multicolumn{8}{|c|}{ Developed countries } \\
\hline 1995-1997 & 343,631 & 12,759 & 30,972 & 3,483 & 35,849 & 29,327 & 17,586 \\
\hline $1998-2000$ & 344,509 & 13,629 & 30,197 & 3,379 & 37,989 & 31,849 & 18,206 \\
\hline 2001-2003 & 351,476 & 14,724 & 29,906 & 3,269 & 38,373 & 34,518 & 18,878 \\
\hline \multicolumn{8}{|c|}{ Developing countries } \\
\hline 1995-1997 & 200,997 & 2,122 & 26,542 & 6,820 & 44,864 & 27,458 & 31,348 \\
\hline $1998-2000$ & 224,409 & 2,342 & 28,875 & 7,621 & 51,194 & 33,631 & 35,553 \\
\hline $2001-2003$ & 250,403 & 2,488 & 30,498 & 8,492 & 56,841 & 39,682 & 40,643 \\
\hline
\end{tabular}

Data presented in 1,000 metric tonnes, with values representing the means of each 3-year period [FAOSTAT/FBS, 2006].

6 times higher than in developing countries (table 4) [FAOSTAT/FBS, 2006].

Meat Production. The global production of pork, poultry, meat (bovine) as well as mutton and goat increased significantly between 1962-1964 and 2001-2003 (fig. 3). The global production of pork has exceeded the production of beef since 1980-1982, and was $57.6 \%$ higher than that of beef in 2001-2003. In 2001-2003, developing countries produced more meat (bovine/beef), mutton and goat, pork, poultry and eggs than developed countries (table 4). The production of beef as well as mutton and goat decreased between 1995-1997 and 2001-2003 in developed countries (table 4). The world production of pork and poultry is high, and production increased by $18 \%$ and $31 \%$, respectively, between $1995-1997$ and 20012003 (table 4). Poultry production was about 7.7 times higher in 2001-2003 than in 1962-1964, and in 20012003 , the production was higher than that of beef or mutton and goat (fig. 3). The main exporter of meat (beef, pork and poultry) in 2005 was Brazil, and the exports amounted to $28 \%$ of total exports [USDA, 2005].

The global production and consumption of meat will probably continue to increase. It is suggested that by 2020 , the production and consumption of meat will be 300 million MT compared to 233 million MT in 2000 [Speedy, 2003].

Factors Influencing the Production of Animal

Source Foods

An increase in income affects the demand for food. In countries with a low gross domestic product (GDP) per capita, more energy is derived from carbohydrates, while those with a high GDP consume more energy from fat [Gerbens-Leenes and Nonhebel, 2006]. In agreement, the percentage of energy (\%E) derived from animal sources (meat, dairy and eggs) is higher in high-GDP countries than in low-GDP countries, but there are indications that the increase is not infinite. It has been shown that more land is required with more affluent diets linked to an increase in fat intake [Gerbens-Leenes and Nonhebel, 2002].

Market forces that impact on the production of dairy products are government policies on the dairy industry, quota restrictions and subsidies [Mitchell, 2001]. All of these influence the production and export of dairy products in countries where dairying is a main agricultural activity. The impact of weather conditions and droughts in New Zealand and Australia, which are major world producers of milk, has led to a decline in milk production during recent years [FAO, 2008a].

According to the United States Department of Agriculture (USDA), factors such as production efficiency, economic development and population growth are the key factors responsible for the growth in meat production [USDA, 2005]. Meat consumption seems to be influenced by wealth and generally increases with an increase in the GDP of a country [Speedy, 2003]. There are, however, exceptions such as the Latin American countries where the consumption of meat is high in relation to the GDP [Speedy, 2003]. Lower production costs in Brazil have contributed to the growth in the meat export industry in this country [USDA, 2005]. 
Table 5. Worldwide production of fish oil

\begin{tabular}{lrrrrrrrrrr}
\hline & 1997 & 1998 & 1999 & 2000 & 2001 & 2002 & 2003 & 2004 & 2005 & $\%$ of total \\
\hline Peru & 330.0 & 123.0 & 514.8 & 587.3 & 302.9 & 188.9 & 206.2 & 349.8 & 290.4 & 32.4 \\
Chile & 206.0 & 106.7 & 201.4 & 180.2 & 141.1 & 128.5 & 130.2 & 195.3 & 168.9 & 18.9 \\
Denmark & 131.1 & 136.1 & 129.3 & 140.3 & 123.6 & 102.6 & 117.8 & 100.0 & 82.3 & 9.2 \\
USA & 128.5 & 101.2 & 129.8 & 87.2 & 126.7 & 95.6 & 88.8 & 81.4 & 71.5 & 8.0 \\
Japan & 10.9 & 75.5 & 68.5 & 59.8 & 63.0 & 64.2 & 67.0 & 68.2 & 62.7 & 7.0 \\
Others & 362.9 & 331.3 & 349.0 & 252.2 & 330.2 & 265.2 & 324.2 & 252.0 & 219.3 & 24.5 \\
Total & $1,169.4$ & 873.8 & $1,392.8$ & $1,307.0$ & $1,087.5$ & 845.0 & 934.2 & $1,046.7$ & 895.1 & 100.0 \\
\hline
\end{tabular}

Data presented in 1,000 metric tonnes [FAO/Fisheries and Aquaculture Information and Statistics Service, 2007].

Poultry production costs have increased significantly between 2000 and 2008 as a result of an increase in the cost of the feed [FAO, 2008b]. In 2001-2003, the production of eggs was more than twice as high in developing countries (about 41 million MT) as in developed countries (about 19 million MT) [FAOSTAT/FBS, 2006]. To produce poultry and eggs, less land is required $\left(7.3 \mathrm{~m}^{2}\right.$ year $\mathrm{kg}^{-1}$ and $3.5 \mathrm{~m}^{2}$ year $\mathrm{kg}^{-1}$, respectively) than to produce other animal source foods such as beef $\left(20.9 \mathrm{~m}^{2}\right.$ year $\left.\mathrm{kg}^{-1}\right)$ and pork $\left(8.9 \mathrm{~m}^{2}\right.$ year $\left.\mathrm{kg}^{-1}\right)$ [Gerbens-Leenes and Nonhebel, 2002].

\section{Production of Fish Oil and Fish}

\section{Production Statistics}

Fish is also a source of fat in the human diet, and the main source of the LCPUFAs, EPA and DHA.

Production of Fish Oil. The total production of fish oils is about 1 million tonnes per year, and it seems to have stabilized at this level (table 5). In 2006, it was estimated that $87 \%$ of all fish oil was used by the aquaculture industry to produce feed, and salmon farming alone used approximately $33 \%$ of all fish oil produced. The remaining $13 \%$ was processed into products for human consumption. A sustainable utilization of fishery resources will not allow a permanent increase in the production of fish oils based on available fishery resources. The most important source of fish oil is the Peruvian anchovy [IFFO, 2008a].

The demand for fish oil in aquaculture has been increasing since it is a main source of essential fatty acids and a key source of energy [Tacon, 1994]. However, increasing demand and increasing prices of fish oil are forcing the industry to look for alternative sources of oil. In early 2008 , the price of fish oil reached 1,700 USD per tonne, compared to 886 USD per tonne a year earlier. This is the same picture as seen for vegetable oils, such as soybean oil [GLOBEFISH, 2008].

The aquaculture industry is continuously working to reduce the reliance on fish oils and is increasing the use of vegetable oils in aquaculture feeds. A number of studies have shown that both fishmeal and fish oil can partially be replaced by vegetable alternatives. It was shown that a total replacement has a negative effect on the growth of rainbow trout [Drew et al., 2007], but this finding was not confirmed by others [Piedecausa et al., 2007]. However, both studies showed that the fatty acid profile of the fish fillets reflected the fatty acid profile of the feed. Fish given feeds low in fish oil had a low level of EPA and DHA in their fillets. At the same time, the levels of dioxin and dioxin-like polychlorinated biphenyls were also at significantly lower residual concentrations in the diets and the fillet.

The increased knowledge regarding the health benefits of fish oil, in particular the long-chain $n-3$ fatty acids EPA and DHA, has increased the demand for marine oils for direct human consumption, mainly as fish oil capsules.

Efforts to develop an anchovy market for human consumption are increasing. It is expected that the Peruvian and international market for anchovy will grow. However, it is not expected that this shift will affect the output of fishmeal and fish oil since the volumes will be small compared to the total volumes of anchovy.

Although the aquaculture industry is growing rapidly, it is, according to the International Fishmeal and Fish Oil Organization (IFFO), expected that the rapid shift to alternative oils will not significantly increase the demand of fish oils for the aquaculture industry. 


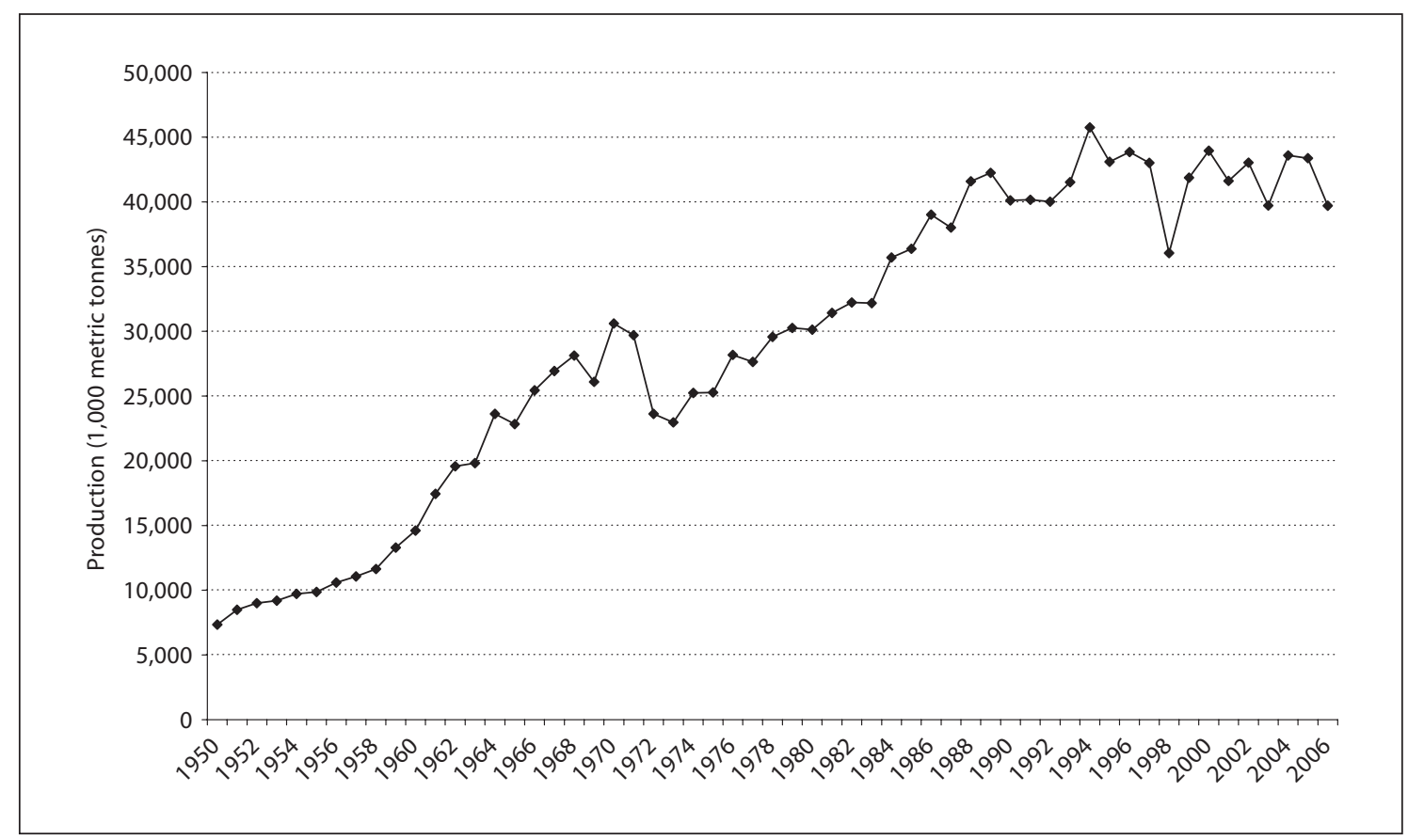

Fig. 4. Total production (capture and aquaculture) of fish between 1950 and 2006 (fish included in total production: salmon, trout, smelt, herring, sardine, anchovy, tuna, bonito and billfish) [FISHSTAT Plus, 2008].

At the moment, fish oil is the only reliable source of EPA and DHA, but new technologies might allow the production of these fatty acids from other sources such as algae.

Production of Fish (Capture and Aquaculture). There has been a steady increase in the production (capture and aquaculture) of fish since 1950, but a sharp decrease in production was observed in 1998. The fish included in the total production figures shown in figure 4 are salmon, trout, smelt, herring, sardine, anchovy, tuna, bonito and billfish. Production levels increased to 43,953,212 MT in 2000, but decreased again to 39,698,422 MT in 2006.

The production of herrings, sardine and anchovy showed large variations between 1995 and 2006, reaching a peak in 2000 [FISHSTAT Plus, 2008]. In 2006, the production of these fish species was $23.4 \%$ lower than the figure for 2000. The production of salmon, trout and smelt increased by $31.4 \%$, and for tuna, bonito and billfish the increase was $10.7 \%$. A decrease in the production of other fish (miscellaneous pelagic) has been observed since 1996 (with a brief increase in 2001) [FISHSTAT Plus, 2008].

In 2003 , the total world production of fish was 132.5 million tonnes, and of these, 104.2 million tonnes were available for human consumption: 24.4 million tonnes in developed countries and 79.8 million tonnes in developing countries [FAO, 2005].

Factors Influencing the Production of Fish

Consumer demand influences the production of fish. Retail stores are growing globally and as a result, are influencing the availability of fish. These supermarkets buy in big quantities and may have contracts with fishing vessels to produce the fish required to meet consumer demands [Nierentz, 2004]. In developing countries, the demand for fish is growing.

Climate change in different parts of the world could impact on the production of fish in future. The Intergovernmental Panel on Climate Change predicted a rise in temperature of $1-2.5^{\circ} \mathrm{C}$ by 2030 [FAO, 2008c]. In Africa, the rising temperatures of the water will further deplete fish stocks already under threat. In Asia, the inundation of coastal areas will affect the aquaculture industry, especially in heavily populated areas. Climate changes in Europe will also affect the distribution of species with an increase in production in the northern waters of the North Atlantic and lower production in the south. In North America, a northward shift of species will also be observed, and cold water fisheries will be negatively affected [FAO, 2008c]. 


\section{Global Trends in Fat Supply and Intake Data}

\section{Introduction}

In this section, data is presented on the trends in dietary fat supply and fatty acid intake in different regions of the world. Information from FAO FBS was used for the presentation of data on energy, protein and fat supply, and for the calculation of the distribution of energy from protein, fat and alcoholic beverages [FAOSTAT/FBS, 2006]. The contribution of different commodities to fat supply is also shown. In addition to the data from the FAO FBS, some data from individual dietary surveys (IDS) will be provided.

In the interpretation of results from FBS and IDS, it is important to acknowledge the characteristics and limitations of each methodology. FBS provide supply data on energy, protein and fat as well as specific food commodities at the national level and do not represent actual consumption of these foods at the individual level. In agreement with FBS, household budget surveys (HBS) also represent data on the entire population and country, and collect data on purchased food quantities [Serra-Majem et al., 2003]. HBS tend to overestimate intake as provision is not made for storage, consumption of food by visitors and under-recording of intakes [Serra-Majem et al., 2003]. Comparing dietary data from FBS, HBS as well as IDS undertaken in Canada, Finland, Poland and Spain, SerraMajem et al. [2003] showed that HBS underestimate dietary intake data compared to FBS by $20 \%$, but overestimate the consumption of foods such as bread, potatoes, pulses, vegetables, fruit, milk and vegetable oil compared to IDS. The same methodologies, i.e. 24-hour recalls or records, were used to collect data for the IDS in the different countries studied by Serra-Majem et al. [2003]. The mean energy and fat intakes determined by means of FBS were $55.2 \%$ higher for energy and $65.3 \%$ for fat compared to IDS. Differences between countries were observed.

The study of Serra-Majem et al. [2003] showed that there is a tendency for FBS to overestimate the consumption of dairy products by $43 \%$ compared to IDS, while the difference between FBS and HBS varied between 12 and $45 \%$. HBS underestimates intakes of fish, meats, pulses and vegetables, while it overestimates sugar, honey and cereals compared to IDS.

One of the advantages of using the FAO FBS is the fact that the data are comparable across countries as the methodology used for the collection of the data is standardized. Information from FBS is valuable for the development of dietary guidelines as they provide information on nutrient and food availability at the national level. IDS, in contrast, collect dietary intake data at the individual level, providing information on age and gender, and are therefore valuable in identifying at-risk populations. Information from IDS is also important for the formulation of a national nutrition policy [Serra-Majem et al., 2003].

One of the difficulties of comparing IDS data between countries is the use of different dietary research methodologies for the collection of dietary intake data. Although the 24-hour recall is often used in large epidemiological studies, the application of the methodology could differ. There are also differences in the results obtained with a quantitative food frequency questionnaire (QFFQ) and 24-hour recalls [Gibson, 2005]. QFFQ often tend to overestimate dietary intake, while 24-hour recalls tend to underestimate dietary intakes. QFFQ give an idea of the habitual dietary intakes of the individual, but a single 24hour recall should only be used to describe the dietary intake of a group [Gibson, 2005]. The availability of country-specific food composition databases and the differences between food composition databases in nutrient composition of similar foods also pose challenges when comparing the dietary intake data across countries.

\section{FBS Data}

\section{Introduction}

As the comparison of information available from IDS from different countries poses several challenges, the use of FBS to compare data between countries offers advantages, as mentioned before. FBS do not provide information on actual consumption within communities or within households, but provide data on the per capita supply per day of energy (kcal), protein (g) and total fat (g) [FAOSTAT/FBS, 2006]. It has been suggested that a more appropriate term would have been 'national average apparent food consumption' instead of food consumption [WHO/FAO, 2003]. Therefore, when the term consumption is used for FBS data, it refers to per capita supply per day data and not to actual consumption patterns.

The unit of measure for energy in the FBS is the kcal. One kcal is equal to $4.184 \mathrm{~kJ}$. Information on the per capita supply per day of energy (kcal/day), protein (g/day) and total fat (g/day) was used to calculate the percentage of energy from protein and total fat. The conversion factors used were $4 \mathrm{kcal}$ for $1 \mathrm{~g}$ protein and $9 \mathrm{kcal}$ for $1 \mathrm{~g}$ total fat [Klensin et al., 1989]. Often the percentage of energy from alcohol is not calculated when the distribution of energy is 
determined, despite the fact that the value for total energy includes the energy contributed by alcohol. The means for the years 1995-1997, 1998-2000 and 2001-2003 were used for the calculations and to present data on trends, and for comparison between regions and countries.

\section{Per Capita Supply per Day of Energy, Protein and Total Fat}

Energy Supply. Energy intake is a reflection of the consumption of the total amount and/or type of food, and high energy intakes are also often associated with a high total fat intake. The trends in mean per capita supply per day of energy ( $\mathrm{kcal} /$ day), protein (g/day) and total fat (g/day) are shown in table 6 for different regions of the world, and indicate an increase over time [FAOSTAT/ FBS, 2006]. The supply of energy nevertheless remains low in developing countries. In 2001-2003, energy supply was $663 \mathrm{kcal} /$ day $(2,774 \mathrm{~kJ} /$ day $)$ higher in developed countries than in developing countries (table 6). Africa had the lowest per capita supply per day of energy in 2001$2003(2,427 \mathrm{kcal} / 10,155 \mathrm{~kJ})$. Large variations $(1,521-3,346$ $\mathrm{kcal} / 6,364-14,000 \mathrm{~kJ})$ in the per capita supply per day of energy were, however, observed within Africa [FAOSTAT/FBS, 2006]. The mean (2001-2003) per capita supply per day of energy for the European Union $(3,534 \mathrm{kcal} /$ day; $14,786 \mathrm{~kJ} /$ day) was higher than for Europe $(3,338$ $\mathrm{kcal} /$ day; 13,966 kJ/day) [FAOSTAT/FBS, 2006]. In the United States, the per capita supply per day of energy for this period was $3,768 \mathrm{kcal} /$ day or $15,765 \mathrm{~kJ} /$ day [FAOSTAT/FBS, 2006]. It is estimated that the per capita supply per day of energy will increase to $2,940 \mathrm{kcal} /$ day $(12,301 \mathrm{~kJ})$ in 2015 and to $3,050 \mathrm{kcal} / \mathrm{day}(12,761 \mathrm{~kJ})$ in 2030 [WHO/FAO, 2003]. In interpreting the energy intakes determined by means of the FBS, it should be kept in mind that FBS overestimates energy intake by about $55.2 \%$ compared to IDS [Serra-Majem et al., 2003].

Protein Supply. The percentage of energy from protein remained fairly stable in developed and developing countries at about $12 \% \mathrm{E}$ and $10 \% \mathrm{E}$, respectively, between 1995-1997 and 2001-2003 (table 6). Differences in the per capita supply per day (2001-2003) of protein were observed between different regions. In developing countries, the per capita supply per day of protein $(68.5 \mathrm{~g} /$ day $)$ was much lower than in developed countries (100.6 g/ day) in 2001-2003. In 2001-2003, the contribution of protein to total energy was the highest in Oceania (12.9\%E).

Total Fat Supply. Globally, the percentage of energy from total fat increased from $23.4 \% \mathrm{E}$ in $1995-1997$ to $25.1 \% \mathrm{E}$ in 2001-2003 (table 6). In developed countries, the percentage of energy from total fat increased by about
Table 6. Trends in the per capita supply per day of energy, protein and total fat

\begin{tabular}{|c|c|c|c|c|c|c|}
\hline & $\begin{array}{l}\text { Energy } \\
\text { kcal/day }\end{array}$ & $\begin{array}{l}\text { Energy } \\
\mathrm{kJ} / \text { day }\end{array}$ & $\begin{array}{l}\text { Protein } \\
\text { g/day }\end{array}$ & $\begin{array}{l}\text { Protein } \\
\% \mathrm{E}\end{array}$ & $\begin{array}{l}\text { Total fat } \\
\text { g/day }\end{array}$ & $\begin{array}{l}\text { Total fat } \\
\% \mathrm{E}\end{array}$ \\
\hline \multicolumn{7}{|l|}{ World } \\
\hline 1995-1997 & 2,756 & 11,531 & 73.8 & 10.7 & 71.7 & 23.4 \\
\hline $1998-2000$ & 2,778 & 11,623 & 74.6 & 10.7 & 74.9 & 24.3 \\
\hline 2001-2003 & 2,798 & 11,707 & 75.4 & 10.8 & 78.0 & 25.1 \\
\hline \multicolumn{7}{|c|}{ Developed countries } \\
\hline $1995-1997$ & 3,205 & 13,410 & 97.9 & 12.2 & 115.6 & 32.5 \\
\hline $1998-2000$ & 3,251 & 13,602 & 98.8 & 12.2 & 118.9 & 32.9 \\
\hline 2001-2003 & 3,320 & 13,891 & 100.6 & 12.1 & 122.6 & 33.2 \\
\hline \multicolumn{7}{|c|}{ Developing countries } \\
\hline $1995-1997$ & 2,625 & 10,983 & 66.8 & 10.2 & 58.9 & 20.2 \\
\hline $1998-2000$ & 2,645 & 11,067 & 67.8 & 10.3 & 62.5 & 21.3 \\
\hline 2001-2003 & 2,657 & 11,117 & 68.5 & 10.3 & 65.9 & 22.3 \\
\hline \multicolumn{7}{|l|}{ Africa } \\
\hline 1995-1997 & 2,371 & 9,920 & 59.3 & 10.0 & 48.3 & 18.3 \\
\hline $1998-2000$ & 2,407 & 10,071 & 60.6 & 10.1 & 49.1 & 18.4 \\
\hline $2001-2003$ & 2,427 & 10,155 & 61.0 & 10.1 & 49.5 & 18.4 \\
\hline \multicolumn{7}{|l|}{ Asia } \\
\hline 1995-1997 & 2,666 & 11,154 & 68.7 & 10.3 & 59.5 & 20.1 \\
\hline $1998-2000$ & 2,674 & 11,188 & 69.3 & 10.4 & 63.7 & 21.4 \\
\hline $2001-2003$ & 2,683 & 11,226 & 70.0 & 10.4 & 68.1 & 22.8 \\
\hline \multicolumn{7}{|l|}{ Europe } \\
\hline $1995-1997$ & 3,196 & 13,372 & 96.6 & 12.1 & 118.6 & 33.4 \\
\hline $1998-2000$ & 3,248 & 13,590 & 98.0 & 12.1 & 120.5 & 33.4 \\
\hline $2001-2003$ & 3,338 & 13,966 & 100.3 & 12.0 & 123.1 & 33.2 \\
\hline \multicolumn{7}{|c|}{ North and Central America } \\
\hline $1995-1997$ & 3,308 & 13,841 & 97.1 & 11.7 & 116.9 & 31.8 \\
\hline $1998-2000$ & 3,405 & 14,247 & 100.1 & 11.8 & 123.2 & 32.6 \\
\hline $2001-2003$ & 3,452 & 14,443 & 101.3 & 11.7 & 128.0 & 33.4 \\
\hline \multicolumn{7}{|c|}{ South America } \\
\hline 1995-1997 & 2,791 & 11,678 & 74.7 & 10.7 & 81.8 & 26.4 \\
\hline $1998-2000$ & 2,826 & 11,824 & 75.9 & 10.7 & 83.2 & 26.5 \\
\hline 2001-2003 & 2,852 & 11,933 & 76.6 & 10.7 & 84.1 & 26.5 \\
\hline \multicolumn{7}{|l|}{ Oceania } \\
\hline 1995-1997 & 2,972 & 12,435 & 95.5 & 12.9 & 112.3 & 34.0 \\
\hline 1998-2000 & 2,926 & 12,242 & 92.8 & 12.7 & 113.0 & 34.8 \\
\hline $2001-2003$ & 2,989 & 12,506 & 96.4 & 12.9 & 114.8 & 34.6 \\
\hline
\end{tabular}

Conversion factors used to calculate $\% \mathrm{E}: 1 \mathrm{~g}$ protein $=4 \mathrm{kcal}$; $1 \mathrm{~g}$ fat $=9 \mathrm{kcal}[$ FAOSTAT/FBS, 2006] .

$1 \%$ from $32.5 \% \mathrm{E}$ in $1995-1997$ to $33.2 \% \mathrm{E}$ in $2001-2003$. Although the percentage of energy from total fat increased from 20.2 to $22.3 \%$ E between 1995-1997 and 2001-2003 in developing countries, the figure is still low in comparison with developed countries. In Africa, a mean per capita supply per day of $18.3 \% \mathrm{E}$ from fat was 
Table 7. Per capita supply per day of total fat and fat from vegetable and animal source foods (2001-2003)

\begin{tabular}{|c|c|c|c|c|c|c|c|c|c|}
\hline & World & $\begin{array}{l}\text { Developed } \\
\text { countries }\end{array}$ & $\begin{array}{l}\text { Developing } \\
\text { countries }\end{array}$ & $\begin{array}{l}\text { North and } \\
\text { Central } \\
\text { America }\end{array}$ & Europe & Oceania & Asia & $\begin{array}{l}\text { South } \\
\text { America }\end{array}$ & Africa \\
\hline Total fat & 78 & 122.6 & 65.9 & 128.0 & 123.1 & 114.8 & 68.1 & 84.1 & 49.5 \\
\hline Vegetable products & $43.1(55.3)$ & $60.0(48.9)$ & $38.6(58.6)$ & $69.6(54.4)$ & $54.2(44.0)$ & $52.8(46.0)$ & $38.7(56.8)$ & $42.6(50.7)$ & $37.9(76.6)$ \\
\hline Animal products & $34.8(44.7)$ & $62.6(51.1)$ & $27.3(41.4)$ & $58.4(45.6)$ & $68.9(56.0)$ & $62.0(54.0)$ & $29.4(43.2)$ & $41.5(49.3)$ & $11.6(23.4)$ \\
\hline Vegetable oil & $30.4(39.0)$ & $48.1(39.2)$ & $25.6(38.8)$ & $54.3(42.4)$ & $43.3(35.2)$ & $39.6(34.5)$ & $26.1(38.3)$ & $33.8(40.2)$ & $22.6(45.7)$ \\
\hline Pork & $10.9(14.0)$ & $12.5(10.2)$ & $10.5(15.9)$ & $9.6(7.5)$ & $16.3(13.2)$ & $8.8(7.7)$ & $12.7(18.6)$ & $6.3(7.5)$ & $0.9(1.8)$ \\
\hline Milk, excluding butter & $6.7(8.6)$ & $16.7(13.6)$ & $3.9(5.9)$ & $17.1(13.4)$ & $17.4(14.1)$ & $13.5(11.8)$ & $3.6(5.3)$ & $9.6(11.4)$ & $3.6(7.3)$ \\
\hline Poultry & $3.2(4.1)$ & $6.0(4.9)$ & $2.4(3.6)$ & $10.3(8.0)$ & $3.9(3.2)$ & $7.5(6.5)$ & $2.1(3.1)$ & $7.7(9.2)$ & $1.0(2.0)$ \\
\hline Butter, ghee & $3.0(3.9)$ & $6.0(4.9)$ & $2.2(3.3)$ & $3.5(2.7)$ & $8.0(6.5)$ & $8.0(7.0)$ & $2.6(3.8)$ & $1.1(1.3)$ & $0.9(1.8)$ \\
\hline Bovine meat & $2.7(3.5)$ & $5.0(4.1)$ & $2.0(3.0)$ & $5.0(3.9)$ & $4.8(3.9)$ & $5.2(4.5)$ & $1.5(2.2)$ & $8.9(10.6)$ & $2.1(4.2)$ \\
\hline Cheese & $1.9(2.4)$ & $7.7(6.3)$ & $0.3(0.5)$ & $8.2(6.4)$ & $8.1(6.6)$ & $6.7(5.8)$ & $0.2(0.3)$ & $1.4(1.7)$ & $0.5(1.0)$ \\
\hline Fish (seafood) & $1.0(1.3)$ & $1.8(1.5)$ & $0.7(1.1)$ & $0.8(0.6)$ & $1.5(1.2)$ & $1.3(1.1)$ & $1.0(1.5)$ & $0.5(0.6)$ & $0.5(1.0)$ \\
\hline Mutton and goat & $0.8(1.0)$ & $1.1(0.9)$ & $0.8(1.2)$ & $0.4(0.3)$ & $1.2(1.0)$ & $7.9(6.9)$ & $0.8(1.2)$ & $0.3(0.4)$ & $0.9(1.8)$ \\
\hline Tree nuts & $0.7(0.9)$ & $1.7(1.4)$ & $0.5(0.8)$ & $1.6(1.3)$ & $1.9(1.5)$ & $1.8(1.6)$ & $0.5(0.7)$ & $0.2(0.2)$ & $0.5(1.0)$ \\
\hline Fish (freshwater) & $0.3(0.4)$ & $0.2(0.2)$ & $0.4(0.6)$ & $0.2(0.2)$ & $0.2(0.2)$ & $0.2(0.2)$ & $0.4(0.6)$ & $0.1(0.1)$ & $0.2(0.4)$ \\
\hline Cream & $0.2(0.3)$ & $1.0(0.8)$ & 0.0 & $0.3(0.2)$ & $1.7(1.4)$ & $0.1(0.1)$ & 0.0 & 0.0 & 0.0 \\
\hline
\end{tabular}

Data presented as the mean supply in grams, with the percentage of fat from total fat in parentheses [FAOSTAT/FBS, 2006].

reported. There are large variations in the per capita supply per day of fat on the continent [FAOSTAT/FBS, 2006]. Data is available for 51 countries (2001-2003) and of those, 23 had a per capita supply per day of fat less than $20 \%$ E. In 12 of the 51 countries, fat supplied less than $15 \% \mathrm{E}$. Gambia was the only country in Africa that was reported to have a fat intake above $30 \% \mathrm{E}(30.3 \% \mathrm{E})$ in 2001-2003 [FAOSTAT/FBS, 2006].

Regions and countries with a high per capita supply per day of energy also had a high supply of total fat (table 6).

As the percentage of energy from protein remained fairly stable between 1995-1997 and 2001-2003, one would expect that the percentage of energy from carbohydrates decreased as fat intake increased.

Alcohol. Information on the per capita supply per day of energy (kcal) from alcoholic beverages is available in the FAO FBS, and this was expressed as a percentage of total energy to provide some indication of the contribution of alcoholic beverages to total energy supply. The per capita supply per day of alcohol was about $1.5 \% \mathrm{E}$ in developing countries and $4.5 \% \mathrm{E}$ in developed countries. This figure represents the mean per capita supply per day of alcohol and includes drinkers and non-drinkers.

Per Capita Supply per Day of Total Fat from Vegetable Oils and Animal Source Foods

Information on the per capita supply per day (g/day) of total fat, fat from vegetable and animal products as well as the amount of total fat supplied by vegetable oils, tree nuts and animal source foods is available from FAO FBS and are summarized in table 7 for the period 2001-2003. This information can be used as an indication of the major food sources of total fat in the diet in different regions or countries of the world. In 2001-2003, vegetable products made the biggest contribution to the per capita supply per day of total fat (g) globally as well as in developing countries, and in developed countries this was animal products (table 7). In developed countries, the per capita supply per day of total fat is about twice as high as in developing countries (table 7). The per capita supply per day of total fat was above $100 \mathrm{~g} /$ day in North and Central America, Europe and Oceania in 2001-2003 (table 7). Although the mean per capita supply per day of total fat in Asia was $68.1 \mathrm{~g} /$ day (mean 2001-2003), large variations were observed within Asia, e.g. the mean supply of total fat in Bangladesh was $25.1 \mathrm{~g} /$ day while it was $148.8 \mathrm{~g} /$ day in Israel [FAOSTAT/FBS, 2006]. The mean per capita supply per day in China was $90.1 \mathrm{~g} /$ day and in India 51.9 $\mathrm{g}$ /day. In Africa, the mean per capita supply per day of fat was $49.5 \mathrm{~g} /$ day (table 7), but large variations were also observed in Africa. The lowest per capita supply per day of total fat was reported for Burundi (only $10.3 \mathrm{~g} /$ day), while the highest supply was reported for Libyan Arab Jamahiriya (106.8 g/day).

Vegetable Oils. Although the developing countries are the main producers of vegetable oils, the per capita supply 


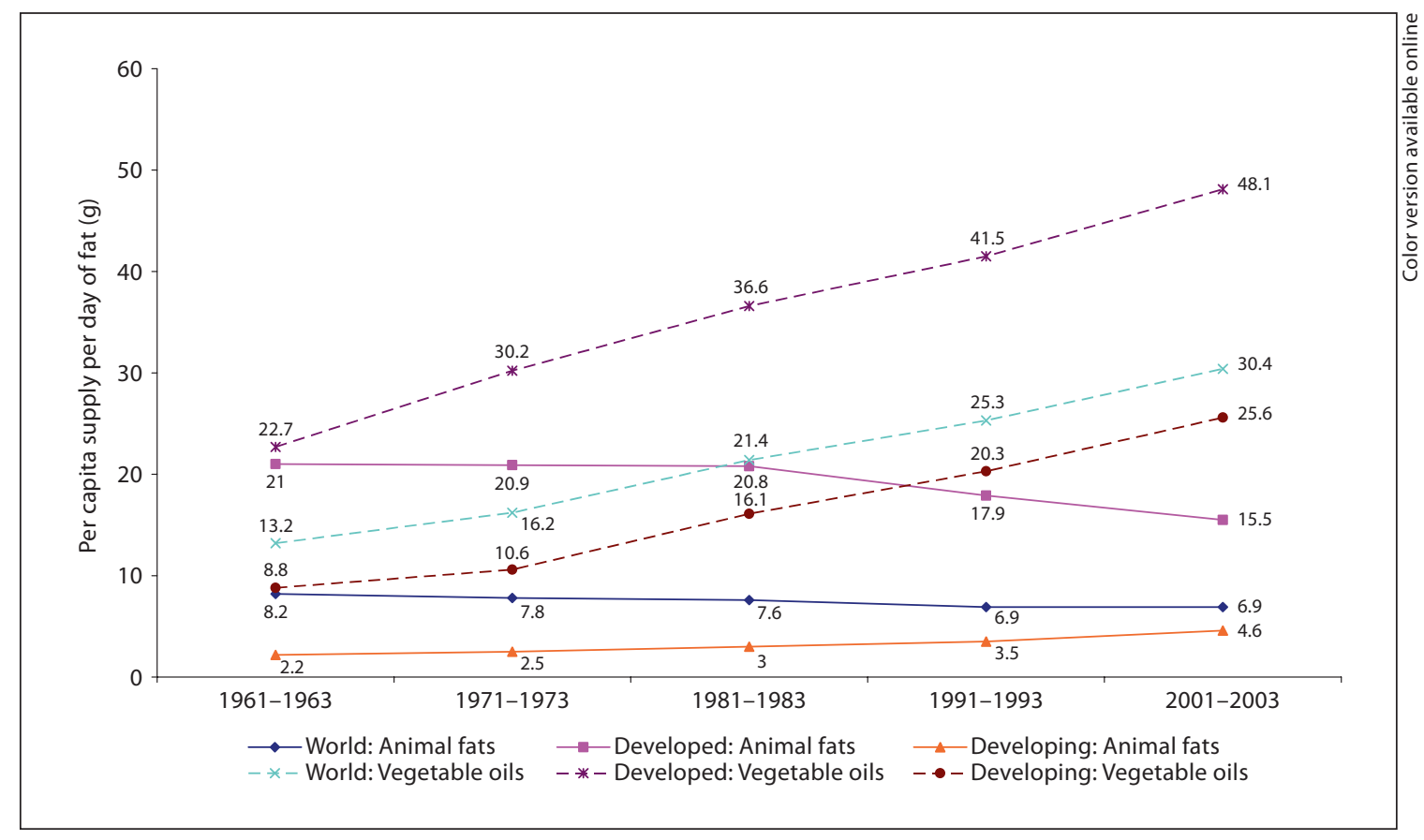

Fig. 5. Per capita supply per day of fat from vegetable oils and animal fats [FAOSTAT/FBS, 2006].

per day of total fat from vegetable oils $(25.6 \mathrm{~g})$ in those countries was about half the amount $(48.1 \mathrm{~g})$ supplied in developed countries (table 7). The percentage contribution of vegetable oils to the per capita supply per day of total fat is, however, almost the same in developed and developing countries (39.2\% and $38.8 \%$, respectively). In Africa, $45.7 \%$ of the per capita supply per day of total fat comes from vegetable oils. Vegetable oils are therefore an important source of fat in the African diet. Sharp increases in the per capita supply per day of fat from vegetable oils were observed in developed (112\%) as well as developing (191\%) countries between 1961-1963 and 2001-2003 (fig. 5).

Tree Nuts. Tree nuts contribute to only a small amount of the per capita supply per day of total fat, with $1.7 \mathrm{~g} /$ day in developed and $0.7 \mathrm{~g} /$ day in developing countries (table 7). The percentage contribution of tree nuts to the per capita supply per day of total fat was less than $2 \%$ for all regions, and highest in Oceania and lowest in South America.

Milk and Cheese. Milk and cheese, especially whole milk and hard cheeses, are important sources of fat in the diet (see 'Fats and Fatty Acid Composition in the Food Supply'), particularly in developed countries (table 7). The production of cheese is about 6 times higher in developed than in developing countries (table 4). Hard-type cheeses, e.g. Cheddar, are not only high in total fat but also a source of SFA in the diet (see 'Fats and fatty acid composition in the food supply'). In developed countries, cheese contributes to $6.3 \%$ of the total fat supply (table 7) and will therefore also make a significant contribution to SFA intake. In addition to cheese, the per capita supply per day of milk (excluding butter) to total fat is also much higher in developed countries (16.7 g/day) than in developing countries ( $3.9 \mathrm{~g} /$ day) (table 7$)$. In Asia, the per capita supply per day of cheese to total fat is low $(0.2 \mathrm{~g} /$ day $)$. (table 7).

Meat. Red meat is an important source of total fat and SFA in a Western-type diet [Wolmarans et al., 1989]. Meat from pigs, cattle and sheep is defined as red meat. In developed and developing countries, pork made the biggest contribution to the per capita supply per day of total fat in 2001-2003, followed by poultry and beef (table 7). The production of pork increased by $26.7 \%$ between 1995 1997 and 2001-2003 in developing countries compared to only $7 \%$ in developed countries (table 4). In Asia and $\mathrm{Eu}-$ rope, pork makes an important contribution to the per capita supply per day of total fat, with $18.6 \%$ and $13.2 \%$, respectively (table 7). South America is an important producer of beef, and beef contributes $10.6 \%$ to the per capita supply per day of total fat (table 7). Although wealth probably influences the consumption of meat, this is not the 
case in Latin America where meat consumption is high in relation to the GDP [Speedy, 2003].

The contribution of mutton and goat to the per capita supply per day of total fat was lower in developed countries $(0.9 \%)$ than in developing countries $(1.2 \%)$ in 2001 2003 (table 7). Oceania had the highest per capita supply per day of fat from mutton and goat (7.9 g/day), and the supply was much higher than in other regions such as North and Central America (0.4 g/day) and Europe (1.2 g/day) (table 7).

In contrast to the sharp increase in the per capita supply per day of total fat from vegetable oils, the per capita supply per day from animal fats decreased by $26 \%$ in developed countries, but increased by $109 \%$ in developing countries between 1961-1963 and 2001-2003 (fig. 5). The per capita supply per day of fat from vegetable oils and animal fats was, however, respectively about 1.9 times and 3.4 times higher in developed than in developing countries (fig. 5).

Poultry. The per capita supply per day of total fat (10.3 g/day) from poultry was highest in North and Central America providing $8 \%$ of the total fat (table 7). In Africa, the per capita supply per day of total fat from poultry was only $1 \mathrm{~g}$ or $2 \%$ per day. The percentage contribution of poultry to total fat intake was higher in developed than in developing countries. In developed and developing countries the production of poultry dropped between 1998-2000 and 2001-2003 (table 4). Less land is required for the production of poultry than for beef [GerbensLeenes and Nonhebel, 2002], making it a good alternative for red meat as an animal source food in countries where there is a shortage of land.

The total fat content of a portion of chicken can vary significantly depending on whether the skin is consumed or not. Poultry also has a better fatty acid profile than red meat, containing more PUFA. More detail is provided in 'Fats and Fatty Acid Composition in the Food Supply' on the fatty acid composition of chicken.

Fish. Fish is the main source of LCPUFAs, EPA and DHA in the human diet. In 'Fats and Fatty Acid Composition in the Food Supply', more detail is provided on the EPA and DHA contents of different fish species. In 20012003 , fish (seafood) contributed to $1.5 \%$ of the per capita supply per day of total fat in developed countries, while this figure was $1.1 \%$ for developing countries (table 7 ). Globally, the per capita supply per day of fat from fresh water fish is only $0.3 \mathrm{~g}$ [FAOSTAT/FBS, 2006]. Between 1950 and 1994, the production of fish (capture and aquaculture) such as salmon, trout, smelt, herring, sardine, anchovy, tuna, bonito and billfish increased, but thereaf- ter started to decrease (fig. 4). In developed countries, the per capita supply per day of fat from fish was higher than in developing countries. The per capita supply per year of fish (seafood) varies significantly in different regions of the world [FAOSTAT/FBS, 2006]. Although the per capita supply per year of fish was $17.8 \mathrm{~kg}$ in Asia, the same figure for Japan was $66.3 \mathrm{~kg}$. In the Maldives, the per capita supply of fish and seafood was $186.0 \mathrm{~kg} /$ year. These figures show that large differences exist within regions.

\section{Individual Dietary Surveys}

\section{Introduction}

The collection of information from volunteers on the amounts and types of food they consume provides quantitative information on energy and nutrient intakes at the individual level (IDS), while FBS provide dietary supply data at the national level. Although there are differences between the methods used for the collection of dietary intake data, both types of information provide valuable information regarding the availability of fat in the diet. Different dietary assessment methodologies and food composition databases can be used for the collection and analysis of dietary intake data in IDS, and this needs to be taken into account when comparing dietary intake data within and between different regions of the world.

Information from a few selected IDS studies performed in different regions of the world, e.g. Europe, the United States, Africa, China and India, are discussed below. An extensive summary of the results from international IDS was not the aim of this background paper.

\section{Country Data}

Europe. Dietary intakes of selected nutrients are presented in table 8 for children, adolescents, adults and the elderly from different European Union countries [Elmadfa et al., 2004]. The information is from the European Nutrition and Health Report 2004, covering the period before May 2004, and shows ranges for intakes of protein, total fat, SFA and PUFA expressed as a percentage of total energy. Cholesterol intakes in milligrams per day are also shown. Although the data presented in table 8 give an indication of nutrient intakes in Europe, limitations, such as the non-uniform collection of data during different years and age categories, were mentioned by the authors as factors that could have influenced the results [Elmadfa et al., 2004].

In general, total fat intakes were high in all age groups. The lowest fat intake was observed in elderly males 
Table 8. Nutrient intakes determined at the individual level in different countries of the European Union

\begin{tabular}{|c|c|c|c|c|c|c|c|c|}
\hline \multirow[t]{2}{*}{ Nutrients } & \multicolumn{2}{|l|}{ Children $^{\mathrm{a}}$} & \multicolumn{2}{|c|}{ Adolescents ${ }^{\mathrm{b}}$} & \multicolumn{2}{|l|}{ Adults $^{c}$} & \multicolumn{2}{|c|}{ Elderly $^{\mathrm{d}}$ (>64 years) } \\
\hline & boys & girls & male & female & male & female & male & female \\
\hline Protein, \%E & $12-17$ & $12-17$ & $13-18$ & $12-17$ & $13-18$ & $13-19$ & $12-17$ & $13-18$ \\
\hline Fat, \%E & $28-41$ & $28-42$ & $31-40$ & $29-40$ & $28-46$ & $30-48$ & $26-44$ & $28-45$ \\
\hline SFA, \%E & $10-17$ & $10-18$ & $12-15$ & $12-16$ & $9-18$ & $9-17$ & $8-20$ & $9-20$ \\
\hline PUFA, \%E & 4-9 & 4-9 & $5-7$ & $4-7$ & 4-8 & 4-9 & $4-9$ & $4-8$ \\
\hline Cholesterol, mg & $104-409$ & $109-369$ & $246-479$ & $181-370$ & $266-655$ & $182-497$ & $223-474$ & $178-387$ \\
\hline
\end{tabular}

Information adapted from results presented in the European Nutrition and Health Report 2004 [Elmadfa et al., 2004].

a Austria, Belgium, Denmark, Finland, Germany, Greece, Hungary, Italy, Norway, Portugal, Spain, UK.

b Austria, Denmark, Germany, Norway, Spain, UK.

${ }^{\text {c }}$ Austria, Belgium, Denmark, Finland, France, Germany, Greece, Hungary, Italy, Norway, Portugal, Spain, Sweden, UK.

d Austria, Denmark, Germany, Hungary, Italy, Norway, Portugal, Spain, UK.

(26\%E), while the upper limit for adult females was $48 \% \mathrm{E}$. The range of intakes reported for total fat clearly indicates that there are differences between countries, but that mean intakes were in general high. FBS data also indicate that the per capita supply per day of total fat (20012003) was high $(38.1 \% \mathrm{E})$ in the European Union (calculated from FAOSTAT/FBS, 2006). In agreement with the high total fat intakes, SFA intakes were also high, and only the lower level of the range of SFA intakes reported for adults and the elderly was below the WHO/FAO [2003] recommendation to consume less than $10 \% \mathrm{E}$ from SFA. The WHO/FAO recommends a PUFA intake of $6-10 \% \mathrm{E}$ per day. Although the upper level of PUFA intakes in countries from the European Union met this guideline, there are clearly also those for whom the intake of PUFA was not enough (table 8). The lower level of intake was below the WHO/FAO recommendation to consume $6-10 \% \mathrm{E}$ from PUFA.

United States. Results from the National Health and Nutrition Examination Survey (NHANES) studies (19712000) showed a decrease in mean fat intakes, expressed as a percentage of total energy intakes, in men and women [Wright et al., 2004]. Estimated means were adjusted to the 2000 United States Census. Between 1971-1974 and 1999-2000, total fat intakes decreased significantly from 36.9 to $32.8 \% \mathrm{E}$ in men and from 36.1 to $32.8 \% \mathrm{E}$ in women. At the same time, SFA intakes also decreased significantly from 13.5 to $10.9 \% \mathrm{E}$ in men and from 13.0 to $11.0 \% \mathrm{E}$ in women. However, during this period, the methodology used for the collection of dietary intake data changed, and since the beginning of 1988, data was also collected for weekend days. The contribution of total fat to energy intake of men and women $(32.8$ and $32.8 \% \mathrm{E}$, respectively) who participated in the NHANES (19992000) study was lower than the figure of $35.3 \%$ calculated from FAO FBS data for the period 1998-2000 [Wright et al., 2004; FAOSTAT/FBS, 2006]. The contribution of alcohol to energy intake is included in the NHANES figures for energy, but in determining the distribution of energy, alcohol was not included in the calculations [Wright et al., 2004]. NHANES data as well as data from FAO FBS showed a diet in the United States that does not meet the WHO/FAO recommendations for total fat $(<30 \% \mathrm{E})$ and SFA $(<10 \% \mathrm{E})$ intake [WHO/FAO, 2003].

Data from FAO FBS showed a high per capita supply per day of total fat (128 g/day) in North and Central America, and this grouping of countries includes the United States (table 7).

Africa. In 1999, a national food consumption survey was undertaken in South Africa on children 1-9 years of age [Labadarios et al., 2005]. A QFFQ and a 24-hour recall were used to collect dietary intake data. The survey showed a significant difference between the mean total fat intakes of those living in urban areas $(26.5 \% \mathrm{E}) \mathrm{com}-$ pared to those in rural areas $(21 \% \mathrm{E})$ [Labadarios et al., 2005]. Saturated fat intake was also higher in urban $(7.3 \% \mathrm{E})$ compared to rural $(5.5 \% \mathrm{E})$ areas. The PUFA to SFA ratio (P/S ratio) of the diet was higher in the rural (1.3) than in the urban (1.0) areas. Total fat and SFA intakes varied between 20 and $30 \% \mathrm{E}$ and between 5 and $9.0 \% \mathrm{E}$, respectively, in the 9 different provinces studied in the country. Higher total fat and SFA intakes were observed in the higher income provinces, where a larger percentage of the population is urbanized. The effect of urbanization on total fat intake was also shown in another South African study on adults [MacIntyre et al., 
2002]. The mean distribution of energy was $22 \% \mathrm{E}$ total fat, $12 \% \mathrm{E}$ protein and $65 \% \mathrm{E}$ carbohydrate for the rural, farm, informal settlement and middle class urban strata. In the upper class urban strata, the distribution of energy was $31 \% \mathrm{E}$ total fat, $13 \% \mathrm{E}$ protein and $57 \% \mathrm{E}$ carbohydrate. Although the figure for the per capita supply per day of fat was $23.1 \%$ E for South Africa in 2001-2003, the IDS mentioned above showed that fat intakes varied and are above $30 \% \mathrm{E}$ in some of the groups studied [MacIntyre et al., 2002; Labadarios et al., 2005; Steyn and Nel, 2006].

Foods of animal origin are important sources of fat in the diet. Protein-rich foods, e.g. red meat, chicken, fish and eggs, contributed to $13.1 \% \mathrm{E}$ in the rural areas compared to $24.6 \% \mathrm{E}$ in the upper class urban areas. The contribution of milk and milk products to energy did not differ between rural and upper class urban areas, while the contribution of added fat to total energy intake $(3.5 \% \mathrm{E})$ differed significantly from that of the upper class urban group (4.6\%E) [MacIntyre et al., 2002].

Dietary intake data from another African country showed high total fat intakes $(34.5 \% \mathrm{E})$ in urban areas, but also relatively high intakes $(29.7 \% \mathrm{E})$ in women from rural areas [Steyn and Nel, 2006]. The intake of SFA varied between $11.6 \% \mathrm{E}$ in the urban and $9.6 \% \mathrm{E}$ in the rural areas. This study was not a national food consumption survey, but included 716 urban and 292 rural women randomly selected from 4 primary regions of Kenya.

Available data from IDS undertaken in Africa showed generally low fat intakes in rural areas and higher fat intakes in urban areas, indicating how urbanization plays a role in total fat intake.

China. Mean total fat intakes in China increased from $18.1 \% \mathrm{E}$ in 1982 to $22 \% \mathrm{E}$ in 1992 and to $29.6 \% \mathrm{E}$ in 2002 [Chen, 1986; Zhai et al., 1996; He et al., 2005; Deng et al., 2008]. In the China Health and Nutrition Survey (CHNS), dietary intake data were collected by means of the weighing method and 3 consecutive 24-hour recalls [Du et al., 2002]. The percentage of energy from fat increased between 1989 and 1997. Mean fat intakes of the population were $19.3 \% \mathrm{E}$ in 1989 and increased to $27.3 \% \mathrm{E}$ in 1997. Differences in intakes were observed between urban and rural areas and also between different income groups. Chinese living in rural areas had a lower fat intake (25.4\%E) than those living in urban areas (32.8\%) in 1997. In addition, the mean fat intake of low-income groups was only $16 \% \mathrm{E}$ in 1989 , but increased to $23 \% \mathrm{E}$ in 1997 , while in high-income groups fat intakes increased from $21.5 \% \mathrm{E}$ to $31.6 \% \mathrm{E}$ during this period.

The percentage of energy from fat consumed by high income groups in China is in agreement with figures re- ported for the European Union and the United States [Elmadfa et al., 2004; Wright et al., 2004]. The tendency for total fat intake to increase seems to continue. Results from one of the project provinces of the CHNS showed that between 1997 and 2000, the percentage of energy from total fat increased in men $(26.3$ and $30.7 \% \mathrm{E})$ and in women (23.1 and 27.7\%E) [Fu et al., 2006]. In 2000, total fat intake remained higher in urban $(32.8 \% \mathrm{E})$ compared to rural $(27.6 \% \mathrm{E})$ areas and in high-income $(34 \% \mathrm{E})$ compared to low-income $(22.8 \% \mathrm{E})$ families. The increase in total fat intake between 1997 and 2000 in the rural areas $(21.9 \% \mathrm{E}$; $27.6 \% \mathrm{E}$ ) was larger than in the urban areas $(31.9 \% \mathrm{E}$; $32.8 \% \mathrm{E}$ ) [Fu et al., 2006]. In 2006, 57.9\% of urban and $38.7 \%$ of rural Chinese taking part in the CHNS study consumed more than $30 \% \mathrm{E}$ from fat compared to $19.8 \%$ and $12.1 \%$, respectively, in 1989 [Popkin, 2008]. The percentage of Chinese who consumed more than $10 \% \mathrm{E}$ from animal sources increased from $38.8 \%$ in 1989 to $67 \%$ in 2006.

The increase in total fat intake in China can be ascribed to an increase in the intake of fat from animal food [Fu et al., 2006]. In the northeast of China, meat intake increased from 33.5 to $43.5 \mathrm{~g} /$ day/person, poultry from 4.1 to $8.9 \mathrm{~g} / \mathrm{day} /$ person, while fish intake decreased from 21.2 to $14.1 \mathrm{~g} /$ day/person between 1992 and 2000. During the same period, vegetable oil intake more or less remained the same at 39.3 compared to $40.1 \mathrm{~g} /$ day/person [Fu et al., 2006]. The food marketing landscape in China is changing at a rapid speed. The sales of supermarkets are growing at $40 \%$ annually, providing access to a wide variety of food [Popkin, 2008].

FBS data also confirm the increase in fat intake in China, showing that the per capita supply per day of energy increased from $22.2 \% \mathrm{E}$ in $1995-1997$ to $27.2 \% \mathrm{E}$ in $2001-$ 2003 [FAOSTAT/FBS, 2006]. Urbanization seems to play an important role in the increase in total fat intake observed in China.

India. India is also a country in rapid transition. It is estimated that its total population will increase from 846.2 million in 1991 to 1,263 million in 2016 [Shetty, 2002]. In 1941, the urban population was $13.9 \%$ of the total population but in 1991, it was $25.7 \%$ [Shetty, 2002]. Differences in total fat intake were observed between the urban high income group $(33.1 \% \mathrm{E})$ and the rural (mean $13.7 \% \mathrm{E})$ population. High total fat intakes were reported in urban upper middle income men $(32 \% \mathrm{E})$ and women (33\%E) from South India [Ghafoorunissa et al., 2002]. A study among urban and semi-urban women in Punjab showed fat intakes of 25.8 and $27.6 \% \mathrm{E}$, respectively [Goyal et al., 2005]. Results from the National Nutrition Monitoring Bureau (1987), however, showed big discrepancies 
in the percentage of energy that came from fat in high-income groups $(33.1 \% \mathrm{E})$ compared to slum dwellers $(16.7 \% \mathrm{E})$ [Shetty, 2002]. Another study on urban slum dwellers in North India showed a median total fat intake of $24.7 \% \mathrm{E}$ in men and $28.7 \% \mathrm{E}$ in women [Misra et al., 2001). SFA intake was 6.6 and $6.5 \% \mathrm{E}$ in men and women, respectively.

Cross-Sectional Data on EPA, Docosapentaenoic Acid (DPA) and DHA Intakes

Cross-sectional dietary intake data from different countries showed large differences in the mean percentage of energy provided by EPA + DPA + DHA [Ueshima et al., 2007]. The contribution of EPA + DPA + DHA to the percentage of total energy was $0.50 \% \mathrm{E}$ in Japan, $0.01 \% \mathrm{E}$ in the People's Republic of China, $0.15 \% \mathrm{E}$ in the UK and $0.08 \% \mathrm{E}$ in the USA. In the countries studied, the percentage of energy from EPA + DHA was also determined, and was as follows: Japan $(0.46 \% \mathrm{E})$, the People's Republic of China $(0.01 \% \mathrm{E})$, the UK $(0.12 \% \mathrm{E})$ and the USA $(0.07 \% \mathrm{E})$.

\section{Fat Intake and Dietary Transition}

The nutrition transition is probably taking place at a much faster rate in developing countries than observed earlier in developed countries [Popkin, 2002]. In this regard, the increase in obesity is of special concern [Popkin and Gordon-Larsen, 2004]. Although an increase in total fat intake is observed with urbanization in developing countries, such as Africa, China and India, this is only one aspect of the nutrition transition. Other changes in diet and lifestyle, e.g. an increase in refined carbohydrate intake and a decrease in physical activity, have also been observed [Popkin and Gordon-Larsen, 2004]. More research is therefore warranted to understand the effect of an increase in the intake of total fat on the incidence of non-communicable diseases in developing countries [Popkin, 2002].

\section{Fats and Fatty Acid Composition in the Food Supply}

\section{Introduction}

Data from FBS showed that vegetable oils and animal source foods are the main contributors to total fat, while nuts also make a small contribution (table 7). Information on the energy and nutrient composition of food is available in country-specific food composition databases. The aim with country-specific food composition databases is to make special provision for traditional foods, indigenous foods and local recipes. There are many fac-

Trends in Food Production, Intake and Composition tors that can influence the nutrient composition of foods, e.g. different breeding practices, soil, seasonal variation, sampling procedures and the methodology used for the analysis of the food [Greenfield and Southgate, 2003]. It is therefore not possible to always compare the nutrient composition of individual foods between different food composition databases. The impact of these factors on the comparison of dietary intake data between countries has already been alluded to. Cost implications and a shortage of appropriately trained food composition database compilers, accredited analytical laboratories and well-trained laboratory staff make it difficult in some countries to update food composition databases regularly. This impacts on the ability to provide users of the food composition database with the latest information on the nutrient composition of foods, especially the fatty acid composition of foods. Despite all the limitations of food composition databases, a food composition database remains a valuable tool for the analysis of dietary intake data at the individual level and for monitoring changes in the fat supply in a country. The energy and nutrient data in food composition databases represent average values and should not be regarded as absolute.

The International Network of Food Data Systems (INFOODS) of the FAO provides a directory of international food composition databases on their website (www. fao.org/infoods/directory_en.stm). The aim of INFOODS is to stimulate and coordinate efforts to improve the quality and availability of food composition data at the international level.

The USDA Agricultural Research Service provides extensive information on the nutrient composition of foods. Nutrient values of 7,412 food items are available online from the USDA National Nutrient Database for Standard Reference [USDA, 2008]. Nutrient information from the USDA National Nutrient Database for Standard Reference, Releases 20 (2007) and 21 (2008), was mainly used as references for information on the nutrient composition of vegetable oils, nuts and animal source foods, as the nutrient information from this database is easily accessible online [USDA, 2007, 2008].

\section{Fatty Acid Composition of Vegetable Oils and Margarine}

\section{Vegetable Oils}

The fatty acid composition of different vegetable oils is presented in figure 6. Information on the fatty acid composition of these vegetable oils was obtained from USDA, 


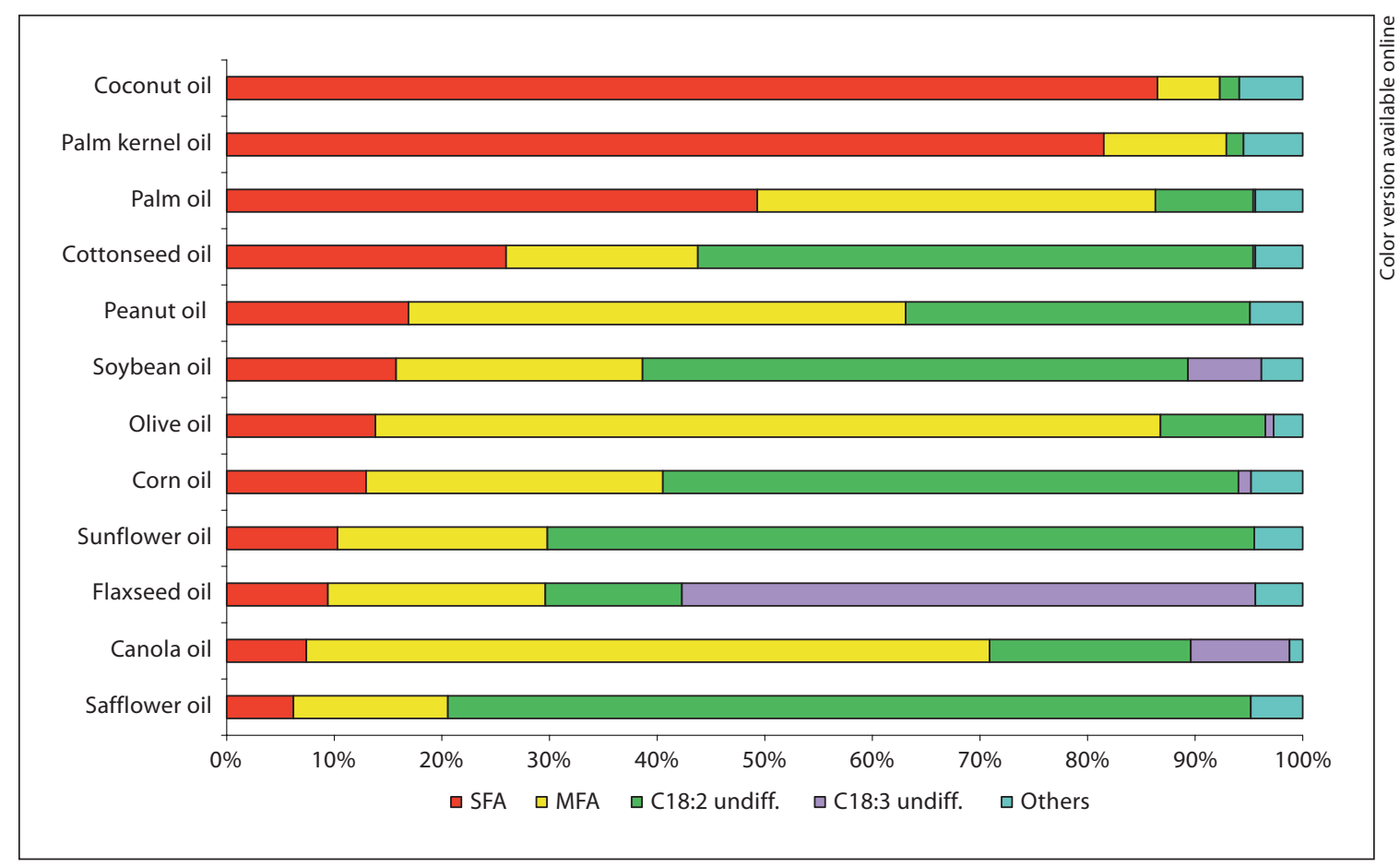

Fig. 6. Fatty acid composition of different vegetable oils (values for C18:2 and 18:3 undifferentiated; others include PUFA other than 18:2 and 18:3 as well as non-fatty acid components) [prepared from USDA, 2008].

National Nutrient Database for Standard Reference, Release 21 [USDA, 2008]. In order to calculate the contribution of non-fatty acid components and 'other' PUFA to the total fat content of vegetable oils, the sum of SFA, MUFA, C18:2 and C18:3 was subtracted from 100, and this value is also shown in figure 6 for the individual vegetable oils.

Coconut oil has the highest content of SFA and is especially high in lauric acid (C12:0; $44.6 \mathrm{~g} / 100 \mathrm{~g})$ and myristic acid (C14:0; $16.8 \mathrm{~g} / 100 \mathrm{~g})$. Palm kernel oil is also high in lauric acid and myristic acid (47 g/100 $\mathrm{g}$ and $16.4 \mathrm{~g} / 100 \mathrm{~g}$, respectively) [USDA, 2008]. Although coconut oil and palm kernel oil are not consumed as such, these vegetable oils are often used in the production of processed foods.

Palm oil contains 49.3\% SFA, 37\% MUFA and 9.3\% PUFA, and has a high palmitic acid (C16:0, $43.5 \mathrm{~g} / 100 \mathrm{~g})$ content [USDA, 2008]. The other SFA present in palm oil are stearic (4.3\%) and myristic acid (1\%). One of the fractionation products of palm oil is palm stearin, which is a solid fat, while palm olein is a liquid oil [American Palm Oil Council, 2008]. Palm stearin contains approximately $60 \%$ SFA and the main SFA are palmitic acid (54\%), stearic acid (5\%) and myristic acid (1\%) [American Palm Oil Council, 2008]. Palm stearin is used in the production of margarine, where a more solid form of fat is required without hydrogenation of the vegetable oils [American Palm Oil Council, 2008]. Palm oil is used for frying, vanaspati and in the production of trans-free margarines and shortenings. Non-food uses of palm oil and palm kernel oil are e.g. soaps, candles, cosmetic products and as fuel for modified cars [American Palm Oil Council, 2008].

Safflower oil and sunflower oil are high in LA, about 75 and $65 \mathrm{~g} / 100 \mathrm{~g}$ oil, respectively [USDA, 2007]. Information on the fatty acid composition of modified varieties of safflower oil and sunflower oil are available in the USDA Nutrient Database with varying amounts of LA and oleic acid [USDA, 2008]. High-LA sunflower oil contains $65.7 \mathrm{~g} / 100 \mathrm{~g} \mathrm{LA}$ and $19.5 \mathrm{~g} / 100 \mathrm{~g}$ MUFA. In contrast, mid-oleic and high-oleic sunflower oil contain higher amounts of oleic acid $(57 \mathrm{~g} / 100 \mathrm{~g}$ and $82.6 \mathrm{~g} / 100 \mathrm{~g})$ and lower amounts of LA $(28.9 \mathrm{~g} / 100 \mathrm{~g}$ and $3.6 \mathrm{~g} / 100 \mathrm{~g}$, respectively) [USDA, 2008]. Standard sunflower oil high in LA is mainly used as a cooking oil in households. More recently, high-oleic sunflower oil has been introduced in the food chain because the risk of oxidation is less than with standard sunflower oil high in LA.

Soybean oil as well as corn oil and cottonseed oil contain about 50\% LA. Soybean oil also contains small 
amounts of C18:2n-6 trans, trans [USDA, 2007] produced by the high-temperature deodorization process. Soybean oil is widely used for cooking and also in the production of mayonnaise, imitation dairy and in commercially baked goods. Partially hydrogenated soybean oil can be used in the production of margarine.

Olive oil is a good source of oleic acid, about $71 \%$ [USDA, 2007]. One of the main characteristics of the typical Mediterranean diet is the use of olive oil [Nestle, 1995]. Different grades of oil are extracted from olives: virgin oil refers to oil produced by physical means and no chemical treatment; refined means that the strong flavors in the oil are neutralized by chemical treatment; pomace oil refers to the oil extracted from the pomace, the remnant solid that remains after the oil is extracted from the olive paste, using chemical solvents [Wikipedia, 2009]. Pomace oil is not generally sold as such, but mixed with some virgin production oil. The words used in production and for labeling purposes can be confusing. The International Olive Oil Council uses the following terminology for labeling purposes of olive oil:

- Extra-virgin olive oil comes from oil produced by the virgin oil method and contains no more acidity than $0.8 \%$. This oil cannot contain any refined olive oil and is regarded as of superior taste.

- Virgin olive oil also comes from oil produced according to the virgin oil production method and has an acidity of less than $2 \%$. This oil cannot contain refined olive oil and has a good taste.

- Olive oil is a blend of oil produced by virgin oil production and refined olive oil, and the acidity is not more than $1.5 \%$. This oil commonly lacks a strong flavor.

Canola oil, one of the cultivars of rapeseed oil, has a high content of oleic acid (about 63\%) and contains about 9\% $\alpha$-linolenic acid (ALA) [USDA, 2007]. New varieties of modified canola oil contain much lower ALA concentrations (2-4\%) [Kris-Etherton and Etherton, 2003]. Small amounts of C18:2n-6 trans, trans are present in canola oil [USDA, 2008]. Canola oil also contains small amounts of erucic acid (C22:1n-9), less than $2 \%$ of the total fatty acids [Food Standards Australia New Zealand, 2003]. In contrast, rape and mustard seed contain 30$60 \%$ erucic acid. Myocardial lipidosis in rats has been associated with the consumption of rapeseed oil. Presently, epidemiological studies in humans do not indicate an association between the consumption of rapeseed oil and the same type of myocardial lesions found in rats, or significant myocardial lipidosis [Food Standards Australia New Zealand, 2003]. The provisional tolerable daily in- take for erucic acid is $7.5 \mathrm{mg} / \mathrm{kg} / \mathrm{day}$ or about $500 \mathrm{mg}$ erucic acid/day, and this figure was extrapolated from the 'no adverse effect level' determined for pigs [Food Standards Australia New Zealand, 2003]. Those consuming large amounts of canola oil or rapeseed oil may be at risk of exceeding the provisional tolerable daily intake for erucic acid.

Flaxseed oil or linseed oil is a major source of ALA (about 53\%) [USDA, 2008], and as a result of its high n-3 fatty acid content, it is mainly used as a food supplement and not for food preparation.

\section{Margarine}

The production and uses of specific types of margarine are discussed in Henry [2009]. Four types of 'margarine' are available on the market. When the fat content of the product is at least $80 \%$, the product is called margarine, while products with a fat content of less than $80 \%$ are called fat spreads. Reduced fat spreads contain $60-$ $70 \%$ fat, low-fat spreads $40 \%$ fat and very-low-fat spreads $3-25 \%$ fat.

One of the main health concerns with the production of margarine and fat spreads is the use of partially hydrogenated vegetable oil as this increases the trans fatty acid content of the product [Tarrago-Trani et al., 2006]. As a result of the health concerns about the consumption of trans fatty acids, the food industry searched for alternatives for the production of margarine [Lemaitre et al., 2006; Tarrago-Trani et al., 2006; Henry, 2009].

In 2004, Denmark introduced legislation to restrict the use of industrially produced trans fatty acid in foods to a maximum of $2 \% \mathrm{E}$ [Stender et al., 2006]. Food labeling legislation, effective from January 1, 2006 in the United States, requires that the trans fatty acid content of the food is shown on the label when the content is equal to or more than 0.5 g per serving [Tarrago-Trani et al., 2006]. This requirement excludes the inclusion of fatty acids with conjugated double bonds.

The different methodologies which have been introduced to lower the trans fatty acid content of fats are a modification of the hydrogenation process, plant breeding and genetic engineering of oil seeds, the use and the fractionation of tropical oils, and the interesterification of fats [Karabulut and Turan, 2006; Tarrago-Trani et al., 2006; Henry, 2009]. As different methodologies are available to the food industry for lowering the trans fatty acid content of fats used in the production of margarine, one could expect differences in the fatty acid composition of the margarines/spreads between manufacturers, and thus also between countries [Karabulut and Turan, 2006; 
Table 9. Energy and macronutrient content of nuts

\begin{tabular}{lllllrrrr}
\hline & $\begin{array}{l}\text { Energy } \\
\mathrm{kJ}\end{array}$ & $\begin{array}{l}\text { Total } \\
\text { fat }\end{array}$ & Protein & $\begin{array}{l}\text { Carbohy- } \\
\text { drate }\end{array}$ & Fiber & SFA & MUFA & PUFA \\
\hline Macadamia & 3,005 & 76.1 & 7.8 & 13.4 & 8.0 & 11.9 & 59.3 & 1.5 \\
Pecan & 2,969 & 74.3 & 9.5 & 13.6 & 9.4 & 6.3 & 44.0 & 20.6 \\
Pine & 2,816 & 68.4 & 13.7 & 13.1 & 3.7 & 4.9 & 18.8 & 34.1 \\
Brazil & 2,743 & 66.4 & 14.3 & 12.3 & 7.5 & 15.1 & 24.5 & 20.6 \\
Walnut & 2,738 & 65.2 & 15.2 & 13.7 & 6.7 & 6.1 & 8.9 & 47.2 \\
Coconut (desiccated) & 2,761 & 64.5 & 6.9 & 23.7 & 16.3 & 57.2 & 2.7 & 0.7 \\
Hazel & 2,703 & 62.4 & 15.0 & 17.6 & 9.4 & 4.5 & 46.6 & 8.5 \\
Peanut & 2,448 & 49.7 & 23.7 & 21.5 & 8.0 & 6.9 & 24.6 & 15.7 \\
Almond & 2,499 & 52.8 & 22.1 & 19.3 & 11.8 & 4.0 & 33.7 & 12.6 \\
Cashew & 2,402 & 46.4 & 15.3 & 32.7 & 3.0 & 9.2 & 27.3 & 7.8 \\
Pistachio & 2,391 & 46.0 & 21.4 & 27.7 & 10.3 & 5.6 & 24.2 & 13.9 \\
\hline
\end{tabular}

Data ranked from highest to lowest total fat content, and presented in $\mathrm{g} / 100 \mathrm{~g}$ edible portion [USDA, 2007].

Kandhro et al., 2008]. It is important to note that the health consequences of the consumption of margarines/ spreads produced by these different methods are far from clear. The fatty acid composition of a margarine/spread is also an indication of the types of oil/fat used in the production of the margarine. As an example, the presence of high amounts of lauric and myristic acid and a low trans fatty acid content could suggest that palm oil fractions or coconut oil were blended with hydrogenated vegetable oils to produce margarine [Karabulut and Turan, 2006].

The average trans fatty acid content of margarines/ spreads from the United States was $19.5 \mathrm{~g} / 100 \mathrm{~g}$ in 1992 and decreased to $8.8 \mathrm{~g} / 100 \mathrm{~g}$ in 1999 [Tarrago-Trani et al., 2006]. Currently, information in the USDA National Nutrient Database for Standard Reference shows a trans fatty acid content of $14 \%$ for stick/bar margarine (80\% fat) produced from regular and hydrogenated corn and soybean oils and $3.7 \%$ for a margarine-like vegetable oil spread (60\% fat) in a tub [USDA, 2008]. Information from food labels of 30 margarines purchased from a major food store in Minneapolis-St Paul, Minn., in the United States showed that $67 \%$ of the margarines had a trans fatty acid content of $0 \mathrm{~g}$ per serving, while $28 \%$ contained between 0.5 and 2.5 g per serving [Albers et al., 2008].

The SFA that predominates in margarine is palmitic acid, and for margarine marketed in Turkey values varied between 7.3 and $34.3 \%$ in margarine and between 23.8 and $38.4 \%$ in shortening [Karabulut and Turan, 2006]. In margarines produced in Pakistan, the palmitic acid content varied between 1.9 and 33.8\% [Kandhro et al., 2008]. Analysis of 15 types of margarine and 10 shortenings marketed in Turkey showed that SFA content tends to increase as trans fatty acid content decreases [Karabulut and Turan, 2006]. In future, an increase in SFA intake could result from the use of lower trans fatty acid alternatives in the production of margarines/spreads and shortening. The health implications of this should be investigated.

A lack of information in food composition databases on the trans fatty acid composition of foods is one of the major challenges for food composition database compilers. As changes in fatty acid composition of margarine/ spreads, shortening and vegetable oils occur due to the new production methods, the use of these products could impact on health. Attention should especially be paid to the differentiation between 18:1 and 18:2 trans fatty acids, as the health implications of these fatty acids may differ [Lemaitre et al., 2006].

\section{Fatty Acid Composition of Nuts}

Nuts are high in energy and fat, but are also good sources of protein and fiber (table 9). Data from FBS indicated that globally, nuts are not a major source of fat (table 7). In vegetarian diets, nuts can serve as an important source of protein. Nuts could also replace snack foods such as potato crisps high in fat and energy as nuts are not only a good source of protein, but also provide other nutrients, e.g. vitamin E, folate, copper, and magnesium [Kris-Etherton et al., 1999]. Brazil nuts are a very good source of selenium, while almonds are a good source of 
Table 10. Saturated fatty acid composition of different types of milk

\begin{tabular}{lllllllllll}
\hline & Total fat & SFA & Butyric & Caproic & Caprylic & Capric & Lauric & Myristic & Palmitic & Stearic \\
\hline Cow & 3.3 & 1.9 & 0.08 & 0.08 & 0.08 & 0.08 & 0.08 & 0.30 & 0.83 & 0.37 \\
Goat & 4.1 & 2.7 & 0.13 & 0.09 & 0.10 & 0.26 & 0.12 & 0.33 & 0.91 & 0.44 \\
Human & 4.4 & 2.0 & - & - & - & 0.06 & 0.26 & 0.32 & 0.92 & 0.29 \\
Indian buffalo & 6.9 & 4.6 & 0.28 & 0.15 & 0.07 & 0.14 & 0.17 & 0.70 & 2.00 & 0.68 \\
Sheep & 7.0 & 4.6 & 0.20 & 0.15 & 0.14 & 0.40 & 0.24 & 0.66 & 1.62 & 0.90 \\
\hline
\end{tabular}

Data presented in $\mathrm{g} / 100 \mathrm{~g}$. A dash indicates that no information is available [USDA, 2008].

vitamin E. Other nutrients present in nuts are manganese, phosphorus, zinc, thiamine, riboflavin and niacin.

The total fat and fatty acid composition of nuts differ. Macadamia and pecan nuts have the highest total fat content (table 9). Both have a total fat content above $70 \mathrm{~g} /$ $100 \mathrm{~g}$ of nuts (table 9). The nuts with the highest total fat content are also the ones highest in energy. Coconut is very high in SFA (57.2 g/100 g), and other nuts also high in SFA are brazil (about $15 \mathrm{~g} / 100 \mathrm{~g}$ ), macadamia (about $12 \mathrm{~g} / 100 \mathrm{~g}$ ) and cashew nuts (about $9 \mathrm{~g} / 100 \mathrm{~g}$ ) (table 9). Coconut has a high lauric acid content $(28.6 \mathrm{~g} / 100 \mathrm{~g})$ [USDA, 2008].

In most nuts, the predominant fatty acid is MUFA (table 9). Macadamia, pecan and hazel nuts contain more than $40 \mathrm{~g}$ of oleic acid per $100 \mathrm{~g}$ of nuts [USDA, 2008]. In pine nuts and walnuts, PUFA is the predominant fatty acid. Walnuts have the highest LA content (38.1 g/100 g) and have a P/S ratio of 7.7, while the ratio of LA/ALA is 4.2 [calculated from USDA, 2008]. The high $\mathrm{P} / \mathrm{S}$ ratio is also the reason why walnuts become rancid very quickly.

Health benefits are linked to the consumption of nuts as nuts can also be an important source of protein in the diet, especially for those who do not consume animal source foods. Feeding studies using nuts as part of the cholesterol-lowering test diets reduced total cholesterol (TC) and low density lipoprotein cholesterol (LDL-C) concentrations by about $4-16 \%$ and $9-20 \%$, respectively [Kris-Etherton et al., 1999]. Kris-Etherton et al. [1999] compared the actual cholesterol response of these test diets with the change estimated by predictive equations for blood cholesterol. The actual cholesterol response to the change in fatty acid intake as a result of the test diets was higher than the predicted change, and they concluded that there may be other bioactive components in nuts that contribute to the lipid lowering effect of these diets. Results from the Nurses' Health Study, a large prospective study, showed that the frequent consumption of nuts was associated with a reduced risk of fatal coronary heart disease and non-fatal myocardial infarction [Hu et al., 1998]. The risk for coronary heart disease was about 35\% lower in women who consumed more than 5 units ( 1 unit was equivalent to $1 \mathrm{oz}$ or about $30 \mathrm{~g}$ ) of nuts per week than those women who never or rarely (less than 1 unit per month) ate nuts.

\section{Fatty Acid Composition of Dairy Products}

\section{Milk and Cheese}

In addition to its total fat and SFA content, milk is an important source of other important nutrients, e.g. protein, calcium and folic acid. Cheese, a product usually made from full-fat milk, is an important source of total fat and SFA in the diet.

The amounts of total fat, total SFA and individual SFA present in different types of milk are presented in table 10 . Human milk contains about $4.4 \%$ fat. The total fat contents of sheep milk (7.0 g/100 g), Indian buffalo milk $(6.9 \mathrm{~g} / 100 \mathrm{~g})$ and goat milk $(4.1 \mathrm{~g} / 100 \mathrm{~g})$ are all higher than that of cow milk (3.3 g/100 g) [USDA, 2008]. While whole milk contains about 3.3\% fat, low-fat milk contains about $2 \%$ fat and skimmed milk contains less than $1 \%(0.2 \mathrm{~g} / 100 \mathrm{~g})$ of total fat [USDA, 2008]. Cream (fluid, heavy whipping) contains $23 \mathrm{~g}$ SFA, $10.7 \mathrm{~g}$ MUFA and $1.3 \mathrm{~g}$ PUFA per $100 \mathrm{~g}$ edible portion [USDA, 2008]. The SFA that predominates in milk fat is palmitic acid, and the short-chain SFA butyric acid (C4:0), and caproic acid (C6:0) are also present [USDA, 2008] (table 10).

Information on the total fat and fatty acid content of different types of cheese is available in the USDA Nutrient Database [USDA, 2008]. The total fat content of hardtype cheeses such as Cheddar is high, about 33\% [USDA, 
2008]. Mozzarella cheese (whole milk), often used in the preparation of pizza, has a total fat content of about $22 \%$, while feta cheese used in the preparation of salad, e.g. Greek salad, has a total fat content of about $21 \%$. The hard-type of cheese made from goat milk contains about $36 \%$ fat, while the soft type contains about $21 \%$ fat. The fat content of fat-reduced hard-type cheeses can vary between $11 \%$ and $20 \%$ [USDA, 2008]. In contrast to the high total fat content of the hard-type cheeses, the total fat content of low-fat cottage cheese, a soft-type cheese available in tubs, is about $1 \%$. The consumption of hard-type cheese makes a significant contribution to total fat intake when eaten regularly in large quantities.

Milk is the best source of conjugated linoleic acid (CLA) in the diet. The CLA content of cow milk varies between 0.32 and $3.3 \%$, depending on the diet of the animal. In an all-pasture diet, the CLA content varied between 1.7 and $2.5 \%$, while on a pasture + fish oil diet the CLA content was 3.3\% [Khanal and Olson, 2004]. Cheese is also a source of CLA, and the content in cheese made from cow milk varied between 0.34 and $1.5 \%$, depending on the diet of the cow. The CLA content of cheese made from sheep milk was $0.8-2.0 \%$, and in cheese made from goat milk it was $0.27-0.69 \%$ [Khanal and Olson, 2004].

The production and per capita supply per day of milk and cheese is much higher in developed countries than in developing countries, indicating that in the former, dairy could be an important source of fat in the diet (tables 4 and 7).

\section{Fatty Acid Composition of Livestock}

Data from FBS showed that meat makes an important contribution to the per capita supply per day of total fat (table 7). Cross-sectional data collected in IDS have also shown that red meat is an important source of total fat and SFA in the diet [Wolmarans et al., 1989].

\section{Beef, Mutton and Pork}

The collective name for meat from cattle, sheep and pigs is red meat. The names used for meat from cattle and sheep indicate the age of the animal. Veal refers to flesh from calves less than 14 weeks old, while beef refers to meat from animals 1-2 years old. Lamb refers to the flesh of sheep younger than 6 months, while mutton refers to flesh from sheep older than 6 months [SAMIC, not dated]. The fat from red meat is regarded as an important source of SFA in the diet. Most of the fat in meat is stored as triacylglycerol, but phospholipids, cholesterol and fat- ty acid esters are also present in beef [Scollan, 2003]. Meat is, however, also an important source of other nutrients such as protein, heme iron, thiamine, riboflavin, niacin, pyridoxine and vitamin $B_{12}$. Vitamin $B_{12}$ is only obtained from food of animal origin.

Changes in animal husbandry have been responsible for the changes in fat content of meat over the years. In the United States, before 1850, cattle were typically slaughtered at $4-5$ years of age, and as a result of the practice of fattening cattle in feedlots, it became possible to produce a ready-for-slaughter $545-\mathrm{kg}$ steer with marbled fat in 24 months [Cordain et al., 2005]. Feeding grain to animals in feedlots became the main practice [Cordain et al., 2005]. There are differences in the fatty acid composition of fat from feedlot cattle compared to pasture-fed cattle, and in the former, the absolute amounts of SFA, MUFA and PUFA are higher, while the absolute amount of n-3 PUFA is lower [Cordain et al., 2002]. Game meat has a lower absolute SFA content and a higher absolute n-3 PUFA content than either grain-fed or pasture-fed beef [Cordain et al., 2002]. Health concerns about the impact of total fat intake and the composition of dietary fat have resulted in efforts by the food industry to change meat quality [Scollan et al., 2006].

The factors that influence the total fat content of beef and mutton are the animal (genetics), nutrition (grainfed or pasture-grazing), the meat cut and the fat trimming of the meat cut [Schönfeldt and Welgemoed, 1996; Droulez et al., 2006; Scollan et al., 2006; Van Heerden et al., 2007]. In beef, the fat is present as membrane fat (as phospholipids), intermuscular fat (between the muscles) and as subcutaneous fat (under the skin), while marbling refers to the adipose tissue between the bundles of muscle fibers [Scollan et al., 2006]. Marbling is closely linked to the intermuscular fat (IMF) content of meat. The amount of IMF determines the fat content of the meat, and lean beef has a low IMF content of about 2-5\% [Scollan et al., 2006]. In South African beef, visible intramuscular fat (or marbling) is 1-2\%, compared to the United States where it varies between 1.8-10.4\% [Sayed et al., 1999]. These differences in the fat composition of foods could impact on research outcomes if country-specific food composition databases are not available. The total fat content of meat cuts differs, and analysis of South African beef showed that in animals classified as an age-A animal (no permanent incisors) with a $20 \%$ fat carcass, the total fat content varied between about $9 \%$ in beef fillet and about 34\% in brisket [Schönfeldt and Welgemoed, 1996]. In contrast, fillet from a beef carcass with 13\% fat will have a total fat content of only about $4 \%$. The fat content of different cuts 
of mutton also varies. Chemical analysis of South African lamb showed that there are large differences in the total fat content of different lamb cuts, e.g. shoulder $(9.6 \mathrm{~g} /$ $100 \mathrm{~g})$, loin $(11.3 \mathrm{~g} / 100 \mathrm{~g})$ or leg $(21.9 \mathrm{~g} / 100 \mathrm{~g})$ [Van Heerden et al., 2007].

A major factor that affects the fatty acid composition of adipose tissue and muscle of cattle, sheep and pigs is the total fat content [Wood et al., 2008]. As the deposition of fat increases in the animal, the proportion of LA in muscle decreases [Wood et al., 2008]. Phospholipids, where LA is located, decrease as a proportion of muscle lipids, and the proportion of neutral lipids increase, the latter being higher in SFA and MUFA [Wood et al., 2008].

Chemical analysis of Australian beef, veal, lamb and mutton showed that in muscle meat the total fatty acids comprised 40\% SFA, 42\% MUFA and 18\% PUFA, while in the meat fat these values were 48,45 and $7 \%$, respectively [Droulez et al., 2006]. Information from the USDA Nutrient Database shows that in $100 \mathrm{~g}$ beef tallow there is $49.8 \mathrm{~g}$ SFA, $41.8 \mathrm{~g}$ MUFA and $4 \mathrm{~g}$ PUFA [USDA, 2008]. In $100 \mathrm{~g}$ mutton tallow, the corresponding figures are: $47.3 \mathrm{~g}$ SFA, $40.6 \mathrm{~g}$ MUFA and $7.8 \mathrm{~g}$ PUFA [USDA, 2008].

Oleic acid is the predominant fatty acid in the muscle and adipose tissue of pigs, sheep and cattle, while palmitic acid is the main SFA [Droulez et al., 2006; Scollan et al., 2006; Wood et al., 2008]. In Australian red meat, the trans fatty acids present are mainly trans 11-18:1 [Droulez et al., 2006]. The trans fatty acids are formed in the rumen as a result of the biohydrogenation of PUFA in the diet. Feeding practices influence the production of the trans fatty acids. Grain-fed animals will have a higher trans fatty acid content than grass-fed animals [Droulez et al., 2006]. Lower levels of total fat, SFA and trans fatty acids were found in Australian red meat, which is mainly grass-fed beef [Droulez et al., 2006]. There are small amounts of EPA and DPA present in red meat [Droulez et al., 2006]. In cattle, the long-chain n-6 and n-3 PUFA are found in muscle phospholipids, but not in adipose tissue or muscle neutral lipids. In pigs and sheep, the long-chain n-6 and n-3 PUFA are, in addition to their presence in phospholipids, also found in muscle neutral lipids and adipose tissue [Wood et al., 2008]. Higher levels of EPA and DPA could be expected where pasture-grazing instead of grainfeeding is practiced as the ALA content of grass is about $60 \%$, while grains have a high LA content [Droulez et al., 2006]. Feeding fresh grazed grass compared to silage grass or concentrate also resulted in higher proportions of ALA in the fatty acids of subcutaneous adipose tissue in steers [Wood et al., 2008]. The $\mathrm{P} / \mathrm{S}$ ratio of beef is typically about
0.1 [Scollan et al., 2006]. The P/S ratio of beef decreases with an increase of fatness of the meat [Scollan et al., 2006]. As a result of the biohydrogenation of a large percentage of LA and ALA in the rumen, it is difficult to achieve major changes in the P/S ratio of beef [Scollan, 2003]. Changes in the PUFA content of beef as a result of oxidative changes can have an effect on the appearance and color and also influence shelf life [Scollan, 2003].

Foods derived from ruminants are a good source of CLA. Meat is a source of CLA (18:2cis-9, trans-11) formed in the adipose tissue of ruminants from 18:1 trans vaccenic acid, a biohydrogenation product of C18:2cis- 6 [Wood et al., 2008]. Conjugated LA acid is also synthesized in the rumen from LA or from the endogenous conversion of trans vaccenic acid (trans-11 C18:1) [Khanal and Olson, 2004]. The CLA content of meat fat is higher than that of muscle fat [Droulez et al., 2006; Wood et al., 2008]. The CLA content (almost exclusively cis- 9 and trans-11 C18:2 isomers) of beef varies between 0.12 and $0.80 \%$ fat [Khanal and Olson, 2004]. The diet of the animal affects the CLA content of beef. Grazing cows on pasture or adding plant oils, oil seeds or fish oil to total mixed rations (50\% forage and $50 \%$ concentrate) increased the CLA content of meat [Khanal and Olson, 2004]. The CLA content of lamb varies between 0.35 and 1.7\% [Khanal and Olson, 2004].

Pork has less marbling than beef and mutton. Most of the fat can be found subcutaneous and can be easily trimmed. Information from the USDA Nutrient Database shows that in $100 \mathrm{~g}$ lard there is $39.2 \mathrm{~g}$ SFA, $45.1 \mathrm{~g}$ MUFA and 11.2 g PUFA [USDA, 2008].

The cholesterol content of beef, mutton and pork is about $100 \mathrm{mg} / 100 \mathrm{~g}$ edible portion of meat.

Data from FBS indicate that red meat makes an important contribution to the per capita supply per day of fat, especially in Europe and Oceania (table 7). Red meat intake will therefore have an important effect on the fatty acid composition of diets in these regions of the world.

\section{Poultry}

Since the middle of the twentieth century, chickens have been specifically selected either to lay a high number of eggs or to produce meat [Hall and Sandilands, no date]. The time it now takes before slaughtering weight is reached is about half the time it took 50 years ago [Hall and Sandilands, no date]. In the middle of the 1960s, it took about 68 days for a broiler chicken to reach a slaughter weight of $2 \mathrm{~kg}$, but by 1987 it took approximately 45 days [Jones, 1986]. Factors that influence the carcass composition of broilers are genetics as well as dietary ma- 
Table 11. Total fat, EPA and DHA content of different fish species

\begin{tabular}{|c|c|c|c|c|}
\hline & $\begin{array}{l}\text { Total } \\
\text { fat }\end{array}$ & EPA & DHA & $\begin{array}{l}\text { EPA + } \\
\text { DHA }\end{array}$ \\
\hline Salmon, Atlantic, farmed & 12.4 & 0.690 & 1.457 & 2.147 \\
\hline Anchovy, European, canned in oil ${ }^{1}$ & 9.7 & 0.763 & 1.292 & 2.055 \\
\hline Herring, Atlantic, cooked & 11.6 & 0.909 & 1.105 & 2.014 \\
\hline Salmon, Atlantic, wild, cooked & 8.1 & 0.411 & 1.429 & 1.840 \\
\hline Salmon, chinook, cooked & 13.4 & 1.010 & 0.727 & 1.737 \\
\hline Tuna, bluefin, fresh, cooked & 6.3 & 0.363 & 1.141 & 1.504 \\
\hline Sardine, Pacific, canned ${ }^{1,2}$ & 10.5 & 0.532 & 0.865 & 1.397 \\
\hline Salmon, sockeye, cooked & 11.0 & 0.530 & 0.700 & 1.230 \\
\hline Mackerel, Atlantic, cooked & 17.8 & 0.504 & 0.699 & 1.203 \\
\hline Halibut, Greenland, cooked & 17.7 & 0.674 & 0.504 & 1.178 \\
\hline Trout, rainbow, farmed, cooked & 7.2 & 0.334 & 0.820 & 1.154 \\
\hline Trout, rainbow, wild, cooked & 5.8 & 0.468 & 0.520 & 0.988 \\
\hline Swordfish, cooked & 5.1 & 0.138 & 0.681 & 0.819 \\
\hline Halibut, Atlantic and Pacific, cooked & 2.9 & 0.091 & 0.374 & 0.465 \\
\hline Shrimp, mixed species, cooked & 1.1 & 0.171 & 0.144 & 0.315 \\
\hline Tuna, light, canned in water & 0.8 & 0.047 & 0.223 & 0.270 \\
\hline Grouper, mixed species, cooked & 1.3 & 0.035 & 0.213 & 0.248 \\
\hline Haddock, cooked & 0.9 & 0.076 & 0.162 & 0.238 \\
\hline Catfish, Channel, wild, cooked & 2.9 & 0.100 & 0.137 & 0.237 \\
\hline Catfish, Channel, farmed, cooked & 8.0 & 0.049 & 0.128 & 0.177 \\
\hline Cod, Atlantic, cooked & 0.9 & 0.004 & 0.154 & 0.158 \\
\hline
\end{tabular}

Ranked from highest to lowest EPA + DHA value and presented in g/100 g [USDA, 2007; Lee et al., 2008]

${ }^{1}$ Drained solids. ${ }^{2}$ Tomato sauce.

nipulations [Jones, 1986]. High-energy diets fed to broilers to reach the slaughter weight earlier increased the fat content of the edible portion significantly [Jones, 1986].

Broiler meat produced under the free-range system is not necessarily a product of higher nutritional value than meat produced under the conventional fast-growing system [Ponte et al., 2008]. A higher SFA and MUFA content and a lower PUFA content were found in breast meat from free-range broilers (slaughtering at 81 days) compared to broilers produced from the conventional system and slaughtered between 35 and 42 days [Ponte et al., 2008]. Higher levels of PUFA, n-3 PUFA and a higher P/S ratio, but a lower DHA level were observed in the conventional broilers compared to the meat from broilers produced under the free-range system [Ponte et al., 2008].

The skin of the chicken is high in fat (more than 40\% fat), while dark meat (about 10\% fat) contains about twice as much fat as white meat (about 4\%) [Sayed et al., 1999]. Chicken fat contains 30\% SFA, 45\% MUFA and 21\% PUFA [USDA, 2008].

\section{Health-Related Aspects of Meat}

There are some reservations about the consumption of red meat as red meat contributes to total fat, and especially SFA intake. Palmitic acid, the predominate fatty acid present in red meat, has a cholesterol-elevating effect. Intervention studies with meat, however, did not show a difference in the effect of lean red meat compared to chicken and fish on the plasma lipids of human volunteers [O'Brien and Reiser, 1980; O'Dea et al., 1990; Wolmarans et al., 1999]. O'Dea et al. [1990] showed that it was the fat and not the meat that has the TC- and LDL-Celevating effect.

\section{Fatty Acid Composition of Fish}

Plant leaves and algae are good sources of ALA. In the marine environment, LCPUFA of the $n-3$ series are produced by algae, in particular cold water algae, from ALA [IFFO, 2008b]. Zooplankton living on these algae are consumed by fish, which later are consumed by humans. Oily marine fish has therefore become the most important source of LCPUFA such as EPA and DHA. In table 11, the total fat, EPA and DHA contents of some common fish species are shown. There is a large variation in the total fat content and the fatty acid profile also within the same species caught in the same area. This is mainly due to seasonal variations [Zlatanos and Laskaridis, 2007]. The total fat and fatty acid composition of fish are influenced by the life cycle and factors such as salinity and fatty acid composition of their food [Zlatanos and Laskaridis, 2007]. Some of the best fish sources of $n-3$ fatty acids are sardine (Sardina pilchardus), anchovy (Engraulis encrasicholus) and pickerel (Spicara smaris). These types of fish are common in the Mediterranean diet [Zlatanos and Laskaridis, 2007]. Fatty acid analysis of sardine, anchovy and pickerel showed that the former had the highest fat content at the end of spring/beginning summer (April-June) and the lowest fat content during winter (February). Anchovy and pickerel had the highest fat content at the end of winter/beginning of spring (February-April) with the lowest fat content at the end of summer (August). Palmitic acid and DHA were the 2 main fatty acids present in sardines, anchovy and pickerel, but in some months, DHA levels were higher than palmitic acid levels. In sardines, DHA levels were higher than palmitic acid levels in winter (December and February) compared to summer and autumn, but in anchovy and pickerel, higher DHA levels than palmitic acid levels were observed in April. 
Table 12. Servings of fish (90 g portion) required per week to provide about 250-500 mg EPA + DHA per day

\begin{tabular}{llll}
\hline & $\begin{array}{l}\text { EPA + DHA } \\
\text { mg/90 g portion }\end{array}$ & $\begin{array}{l}\text { Number of 90 g portions } \\
\text { required per week }\end{array}$ & $\begin{array}{l}\text { Mean EPA + DHA provided by } \\
\text { fish portions, mg/day }\end{array}$ \\
\hline Salmon, Atlantic* & 1,932 & 2 & 552 \\
Herring, Atlantic & 1,813 & 2 & 518 \\
Mackerel & 1,083 & 3 & 464 \\
Salmon, Atlantic* plus & 1,932 & 1 & 519 \\
$\quad$ tuna, light canned in water & 243 & 7 & 310 \\
Salmon, Atlantic* plus & 1,932 & 1 & 296 \\
$\quad$ tuna, light canned in water & 243 & 1 & 284 \\
Salmon, Atlantic plus & 1,932 & 1 & \\
$\quad$ cod & 142 & 1 & \\
Cod & 142 & 14 & \\
\hline
\end{tabular}

* Farmed. Source: USDA [2007].

The American Heart Association recommends the consumption of fish, especially fatty fish, at least twice a week [American Heart Association, 2006]. A daily intake of $500 \mathrm{mg} \mathrm{EPA}+\mathrm{DHA}$ per day is recommended for the primary prevention of coronary heart disease [ISSFAL, 2004]. Data from a meta-analysis suggested that a modest intake of 250-500 mg EPA + DHA per day reduced the risk of coronary heart disease death [Lee et al., 2008]. Examples of the type and amount of fish that should be consumed per week to meet this recommendation are provided in table 12. The consumption of two $90 \mathrm{~g}$ portions of fatty fish such as salmon and herring per week will provide about $500 \mathrm{mg}$ of EPA + DHA per day (table 12). One portion of fatty fish per week plus one portion of white/low fat fish will only provide about $300 \mathrm{mg}$ of EPA + DHA per day. The consumption of at least $180 \mathrm{~g}$ of cod per day would be required to consume about $300 \mathrm{mg}$ of $\mathrm{EPA}+\mathrm{DHA}$ per day.

\section{Health Aspects of Fish}

Fish is the main source of the $n-3$ fatty acids EPA and DHA. The beneficial effects of these fatty acids have been shown in several studies [Wang et al., 2006].

As a result of the danger of mercury poisoning, the consumption of king mackerel ( $0.730 \mathrm{ppm})$, shark (0.988 $\mathrm{ppm})$, swordfish $(0.976 \mathrm{ppm})$ and tile fish $(1.450 \mathrm{ppm})$ is not recommended for young children and pregnant and lactating women, as these fish have a particularly high mercury content [FDA/EPA, 2004; US FDA, 2006]. The higher up in the food chain the fish are, the higher the mercury content. In addition, what they eat and how long they live influence the mercury content of fish. Mercury in the air, e.g. from industrial pollution, can accumulate in streams and the ocean, and chemical changes as a result of bacteria in the water transform mercury into methylmercury [FDA/EPA, 2004]. The methylmercury ends up in the fish feeding in these waters [FDA/EPA, 2004].

Fish that have lower levels of mercury are for example hake (0.014 ppm), Atlantic sardine (0.016 ppm), haddock $(0.031 \mathrm{ppm})$, herring $(0.044 \mathrm{ppm})$, Atlantic mackerel (0.050 ppm), cod (0.095 ppm) and salmon (0.014 ppm). The mercury content of Albacore tuna (canned) is much higher $(0.353 \mathrm{ppm})$ than that of canned light meat tuna (0.118 ppm). Therefore, the Food and Drug Administration (FDA) recommends that only 6 ounces (about $180 \mathrm{~g}$ ) of fish per week is eaten when albacore tuna is consumed compared to the recommendation of 12 ounces (about $360 \mathrm{~g}$ ) of fish and shell fish per week [FDA/EPA, 2004]. A new FDA Draft Report on the safety of fish consumption and the possible dangers of mercury contamination is currently under discussion [Layton, 2008]. There are indications that the new FDA recommendations could reverse the current policy of the government of the United States regarding guidelines for the safety of fish consumption by young children and pregnant and lactating women [Layton, 2008].

\section{Fast Foods}

Fast food consumption contributes to an increase in energy and total fat intake and also has a negative effect on dietary quality [Paeratakul et al., 2003]. In addition, 
fast foods are also a source of trans fatty acids in the diet. One of the critical issues regarding studying the association between trans fatty acids and adverse effects on health is a lack of detailed information on the trans fatty acid content of food in food composition databases. Innis et al. [1999] demonstrated large differences in the trans fatty acid composition of snack food, breaded fried chicken and bread. A study undertaken by Stender et al. [2006] also showed a large difference in the amount of industrially produced trans fatty acids (IP-TFA) in French fries and chicken nuggets purchased from McDonald's and Kentucky Fried Chicken outlets in different parts of the world. IP-TFA content varied between less than $1 \%$ of total fat in French fries and chicken nuggets purchased from McDonald's in Denmark and China to more than 23 and $11 \%$, respectively, for those fast foods purchased in New York in the United States. French fries and chicken nuggets bought from Kentucky Fried Chicken in Germany contained $1 \%$ of IP-TFA, while in Hungary the figures were 35 and 31\%, respectively [Stender et al., 2006]. Convenience foods, e.g. crackers, croutons, biscuits, cake mixes, popcorn, pie shells, doughnuts, sauces and gravy are examples of food that could contain more than $2 \mathrm{~g}$ of trans fatty acids per $100 \mathrm{~g}$ of food [Innis et al., 1999]. Large variations are, however, observed in the trans fatty acid content of convenience foods. As an example, the mean trans fatty acid content of a cracker can be $6.4 \mathrm{~g}$ per $100 \mathrm{~g}$ of crackers, but the range could vary between 0.7 and $12.9 \mathrm{~g}$ per $100 \mathrm{~g}$ of crackers. The trans fatty acid content of fast foods and convenience foods depends on the types of oil or fat used in the preparation. Different fats and oils are sometimes mixed, e.g. partially hydrogenated and non-hydrogenated vegetables oils such as coconut oil and palm kernel oil for preparation purposes [Innis et al., 1999]. The type of oil or mixture used in the preparation of foods will determine the trans fatty acid content of the product.

\section{n-3 Enriched Foods}

Today, foods enriched with n-3 fatty acids, e.g. ALA, EPA and DHA, are available on the market. These foods include, for example, margarines enriched with ALA and DHA, milk enriched with EPA and DHA and designer eggs. $\mathrm{n}$-3-Containing eggs can be produced by feeding a fish oil (increase EPA and DHA) or flaxseed diet (increase ALA and DHA) to the chickens [Oh et al., 1991; Ferrier et al., 1995].
These n-3 fatty acid-enriched foods could in future contribute to meeting the recommendations for $\mathrm{n}-3$ fatty acid intake, as the sustainability of the fish sources to meet recommendations for the LCPUFAs is under threat.

\section{Summary and Conclusion}

The fatty acid content of vegetable oils differs, and not all vegetable oils are good sources of MUFA or PUFA. Some vegetable oils such as coconut oil and palm kernel oil are high in SFA. Trans fatty acids are formed when vegetable oils are partially hydrogenated. As a result of the health concerns linked to the consumption of trans fatty acids, the use of partially hydrogenated vegetable oils in the production of margarine is questioned. Industry responded to these concerns by developing alternative methods for the production of margarine that is low in or do not contain trans fatty acids.

Nuts are high in fat, and MUFA is the predominant fat in most nuts. Walnuts seem to be a good choice as they have a high PUFA content but also contain ALA.

Milk and cheese are an important source of fat in the diet of developed countries and also contribute to the intake of SFA, but are also the most important source of CLA in the diet.

The fatty acid composition of meat depends on the cut as well as the fatness of the carcass. Feeding practices also influence the fatty acid composition of meat. Grass-feeding results in higher levels of PUFA than grain-feeding. As a result of biohydrogenation of PUFA, trans fats are formed in the lumen of ruminants.

Fatty fish are the main sources of EPA and DHA in the diet, and the consumption of at least 2 portions of fatty fish per week is recommended to provide the recommendation to consume at least $500 \mathrm{mg}$ of EPA + DHA per day.

Not only the total amount of fat consumed but also the type of fat in the diet has health implications. Changes in the fatty acid composition of foods, as a result of a change in production methods, e.g. for margarine, requires the updating of food composition databases on a regular basis. The latter is required to enable the consumer to have updated information on the fatty acid composition of food and to enable researchers to use the data in the most appropriate manner. 


\section{Acknowledgements}

Mr Jogeir Toppe from the Food Utilization and Marketing Service of the FAO is thanked for his contribution to parts of the text on fish and fish oil production and some information on the fatty acid composition of fish.

The technical assistance of Ms Natasha Danster from the Nutritional Intervention Research Unit of the South African Medical Research Council is acknowledged with appreciation.

\section{Disclosure Statement}

Dr. Wolmarans received a research grant from UNILEVER for analyzing the fatty acid composition of margarine, vegetable oils, fish and fast foods in South Africa.

\section{Appendix: FAO Categorization of Countries}

\section{Developed Countries}

Armenia, Albania, Andorra, Australia, Austria, BelgiumLuxembourg, Bulgaria, Canada, Czechoslovakia, Republic of Azerbaijan, Denmark, Belarus, Estonia, Faeroe Islands, Finland, France, Georgia, Germany (New Lander), Germany Federal Republic, Germany, Bosnia and Herzegovina, Gibraltar, Greece, Holy See, Hungary, Croatia, Iceland, Ireland, Israel, Italy, Kazakhstan, Japan, Kyrgyzstan, Latvia, Liechtenstein, Lithuania, Malta, Monaco, Republic of Moldova, Netherlands, Macedonia, (The Former Republic of Yugoslavia), New Zealand, Norway, Czech Republic, Poland, Portugal, Romania, Russian Federation, Serbia and Montenegro, San Marino, Slovenia, Slovakia, South Africa, Spain, Tajikistan, Sweden, Switzerland, Turkmenistan, USSR, United Kingdom, Ukraine, United States of America, Uzbekistan, Yugoslavia SFR, Belgium, Luxembourg, Channel Islands, Svalbard and Jan Mayen, Isle of Man.

\section{Developing Countries}

Afghanistan, Algeria, American Samoa, Angola, Antigua and Barbuda, Argentina, Bahamas, Bahrain, Barbados, Bangladesh, Bermuda, Bhutan, Bolivia, Botswana, Brazil, Aruba, Belize, British Indian Ocean Territory, Solomon Islands, Brunei Darussalam, Myanmar, Burundi, Antarctica others, Bouvet Island, Cameroon, Canton and Enderbury Island, Cape Verde, Cayman Islands, Central African Republic, Sri Lanka, Chad, Chile, Christmas Island, Cocos (Keeling) Islands, Colombia, Comoros, Congo (Republic), Cook Islands, Costa Rica, Cuba, Cyprus, Benin, Dominica, Dominican Republic, Ecuador, Egypt, El Salvador, Equatorial Guinea, Ethiopia PDR, Falkland Islands (Malvinas), Fiji Islands, French Guiana, French Polynesia, French Southern Territories, Djibouti, Gabon, Gambia, Gaza Strip (Palestine), Ghana, Kiribati, Greenland, Grenada, Guadeloupe, Guam, Guatemala, Guinea, Guyana, Heard and McDonald Islands, Haiti, Honduras, India, Indonesia, Islamic Republic of Iran, Iraq, Côte d'Ivoire, Jamaica, Johnston Island, Jordan, Kenya, Cambodia, Korea (Democratic People's Republic), Republic of Korea, Kuwait, Laos, Lebanon, Lesotho, Liberia, Libyan Arab Jamahiriya, Marshall Islands, Madagascar, Malawi, Malaysia, Maldives, Mali, Martinique, Mauritania, Mauritius, Mexico,
Midway Islands, Mongolia, Montserrat, Morocco, Mozambique, Federal States of Micronesia, Namibia, Naura, Nepal, Netherlands (Antilles), Neutral Zone, New Caledonia, Vanuatu, Nicaragua, Niger, Nigeria, Niue, Norfolk Island, Northern Mariana Island, Pacific Islands Trust Territory, Pakistan, Panama, Papua New Guinea, Paraguay, Peru, Philippines, Pitcairn Islands, Guinea-Bissau, Timor-Leste, Puerto Rico, Eritrea, Qatar, Palau, Zimbabwe, Réunion, Rwanda, Saint Helena, Saint Kitts and Nevis, Saint Lucia, Saint Pierre and Miquelon, Saint Vincent/ Grenadines, Sao Tome and Principe, Saudi Arabia, Senegal, Seychelles, Sierra Leone, Singapore, Somalia, Western Sahara, Sudan, Suriname, Swaziland, Syrian Arab Republic, United Republic of Tanzania, Thailand, Togo, Tokelau, Tonga, Trinidad and Tobago, Oman, Tunisia, Turkey, Turks and Caicos Islands, United Arab Emirates, Uganda, Tuvalu, US Minor Outlying Islands, Burkina Faso, Uruguay, Venezuela, (Bolivar Republic of) Vietnam, Ethiopia, British Virgin Islands, Wake Island, Wallis and Futuna Islands, Samoa, West Bank, Yemen, Democratic Republic of Congo, Zambia, Anguilla, Mayotte, South Georgia/ Sandwich Islands, Palestine (Occupied Territory), China.

\section{North and Central America}

Antigua and Barbuda, Bahamas, Barbados, Bermuda, Aruba, Belize, Canada, Cayman Islands, Costa Rica, Cuba, Dominica, Dominican Republic, El Salvador, Greenland, Grenada, Guadeloupe, Guatemala, Haiti, Honduras, Jamaica, Martinique, Mexico, Montserrat, Netherlands Antilles, Nicaragua, Panama, Puerto Rico, Saint Kitts and Nevis, Saint Lucia, Saint Pierre and Miquelon, Saint Vincent/Grenadines, Trinidad and Tobago, Turks and Caicos Islands, United States of America, British Virgin Islands, US Virgin Islands, Anguilla.

References

Albers MJ, Harnack L, Steffen LM, Jacobs DR: 2006 marketplace survey of trans-fatty acid content of margarines and butters, cookies and snack cakes, and savory snacks. J Am Diet Assoc 2008;108:367-370.

American Heart Association: Diet and Lifestyle Recommendations Revision 2006: A scientific statement from the American Heart Association Nutrition Committee. 2006. http://circ. ahajournals.org/cgi/reprint/CIRCULATIONAHA.106.176158 (accessed 21/10/2008).

American Palm Oil Council: Frequently asked questions. 2008. www.americanpalmoil. com/faq.html (accessed 13/10/2008).

Broeska R. The global oils \& fats market - current drivers, future prospects (OFI Middle East Conference, Cairo, 20-21 March 2007). 2007. www.iasc-oils.org/word\%20docs/The $\% 20$ global\%20oils\%20\%20fats\%20market. doc (accessed on 24/08/2008)

Business Standard: Veg oil prices to rise $20 \%$ in '09. December 25, 2008. http://www.business-standard.com/india/news/veg-oilprices-to-rise-20-in-09/344224/. 
Canola Council of Canada: Canola... growing great 2015 builds on seven by seven success. 2007. www.canola-council.org/uploads/canola growing_great_2015.pdf (accessed 10/09/2008).

Canola Council of Canada: Overview of Canada's canola industry. 2008. www.canolacouncil.org/ind_overview.aspx. (accessed 28/07/2008).

-Chen CM: The national nutrition survey in China, 1982: summary results. Food Nutr 1986; 12:58-60.

-Cordain L, Eaton SB, Sebastian A, Mann N, Lindenberg S, Watkins BA, O'Keefe JH, BrandMiller J: Origins and evolution of the Western diet: health implications for the 21st century. Am J Clin Nutr 2005;81:341-354.

-Cordain L, Watkins BA, Florant GL, Kelher M, Rogers L, Li Y: Fatty acid analysis of wild ruminant tissues: evolutionary implications for reducing diet-related chronic diseases. Eur J Clin Nutr 2002;56:181-191.

Deng ZY, Zhou XQ, Huang YH, Liu DM: Investigation of dietary fatty acids intakes of Chinese people during twenty years. J Food Sci Biotech 2008;27:7-19.

Drew MD, Ogunkoya AE, Janz DM, Van Kessel AG: Dietary influence of replacing fish meal and oil with canola protein concentrate and vegetable oils on growth performance, fatty acid composition and organochlorine residues in rainbow trout (Oncorhynchus mykiss). 12th Int Symp Fish Nutr Feeding, Biarritz, 2007.

-Droulez V, Williams PG, Levy G, Strobaus T, Sinclair A: Composition of Australian red meat 2002. 2. Fatty acid profile. Food Australia 2006;58:335-341. http://ro.uow.edu. au/hbspapers/1 (accessed 09/09/2008).

Du S, Lu B, Zhai F, Popkin BM: A new stage of the nutrition transition in China. Public Health Nutr 2002;5:169-174

-Elmadfa I, Weichselbaum E, Koenig J, Remaut de Winter A-M, Trolle E, Haapala I, Uusitalo U, Mennen L, Hercberg S, Wolfram G, Tricholopoulou A, Naska A, Vassiliki B, Dritsellis E, Rodler I, Zajkás G, Branca F, D’Acapito P, Klepp K-I, Ali-Madar A, De Almeida MDV, Alves E, Roderiques S, Serra-Majem L, Roman B, Sjöström M, Poortvliet E, Margetts B: European Nutrition and Health Report 2004. Ann Nutr Metab 2004;48(suppl 2): 1-16.

Export Processing Zones Authority: Vegetable oil industry in Kenya 2005. 2005, p 15. www. epzakenya.com/UserFiles/File/kenyaVegetableOil.pdf (accessed 14/07/2008).

FAO: Summary of World Food and Agricultural Statistics 2005. Rome, FAO, 2005. www.fao. org/ES/ESS/sumfas/sumfas_en_web.pdf (accessed 27/08/2008).

$\mathrm{FAO} /$ Fisheries and Aquaculture Information and Statistics Service: Fisheries commodities production and trade 1976-2005. FISHSTAT Plus - universal software for fishery statistical time series (online or CD-ROM). Rome, FAO, 2007. http://www.fao.org/fi/ statist/FISOFT/FISHPLUS.asp.
FAO: Food outlook. Global market analysis: milk and milk products. 2008a. www.fao. org/docrep/010/ai466e/ai466e09.htm (accessed 20/10/2008)

FAO: Food outlook. Global market analysis: meat and meat products. 2008b. www.fao. org/docrep/010/ai466e/ai466e08.htm (accessed 20/10/2008).

FAO: Climate change adaptation and mitigation in the food and agriculture sector. 2008c. ftp://ftp.fao.org/docrep/fao/meeting/013/ ai782e.pdf (accessed 27/08/2008).

FDA/EPA: Backgrounder for the $2004 \mathrm{FDA} / \mathrm{EPA}$ consumer advisory: what you need to know about mercury in fish and shellfish. 2004 www.fda.gov/oc/opacom/hottopics/mercury/backgrounder.html (accessed 22/08/2008).

FAOSTAT/FBS: Food Balance sheets (last updated 3 March 2006). 2006.

-Ferrier LK, Caston LJ, Leeson S, Squires J, Weaver BJ, Holub BJ: $\alpha$-Linolenic acid- and docosahexaenoic acid-enriched eggs from hens fed flaxseed: influence on blood lipids and platelet phospholipid fatty acids in humans. Am J Clin Nutr 1995;62:81-86.

FISHSTAT Plus (Fisheries and Aquaculture Information and Statistics Service): Total fishery production 1950-2006. FISHSTAT Plus - universal software for fishery statistical time series (online or CD-ROM). 2008. Food and Agriculture Organization of the United Nations. www.fao.org/fi/statist/ FISOFT/FISHPLUS.asp.

Food Standards Australia New Zealand: Erucic acid in Food: a toxicological review and risk assessment. Technical Report Series 21. 2003. www.foodstandards.gov.au/_srcfiles/ Erucic\%20acid\%20monograph.pdf (accessed 22/10/2003).

Fu J, Wang Z, Wang B: Transitions of food groups and nutrients in the northeast of China: a 3year-interval's follow-up study. Internet J Nutr Wellness 2006;2:11.

Ghafoorunissa Vani A, Laxmi R, Sesikeran B: Effects of dietary $\alpha$-linolenic acid from blended oils on biochemical indices of coronary heart disease in Indians. Lipids 2002; 37:1077-1086

Gerbens-Leenes PW, Nonhebel S: Consumption patterns and their effects on land required for food. Ecol Econ 2002;42:185-199.

Gerbens-Leenes PW, Nonhebel S: Food consumption and economic development, a spatial and temporal comparison. 2006. http://dissertations.ub.rug.nl/FILES/faculties/science/2006/p.w.gerbens-leenes/c6.pdf (accessed on 10/09/2008).

Gibson RS: Principles of Nutritional Assessment, ed 2. New York, Oxford University Press, 2005

Global Oils and Fats Business Magazine: POTSDubai. 2008;5:1-3.

GLOBEFISH: Fish Oil Market Report - July 2008. 2008. www.globefish.org/dynamisk. php4?id=4546.
Goyal U, Sadana B, Verma S: Contribution of various foods to fat and fatty acids intake among urban and semi-urban women of Punjab. J Hum Ecol 2005; 18:217-220.

Greenfield H, Southgate DAT: Food Composition Data: Production, Management and Use, ed 2. Rome, FAO, 2003.

Hall C, Sandilands V:. Public Attitudes to the welfare of broiler chickens (undated). Land Economy Working Paper Series 13. http:// ageconsearch.umn.edu/bitstream/45998/2/ Work13Hall.pdf (accessed 13/01/2008)

Hawkes C: Uneven dietary development: linking the policies and processes of globalization with the nutrition transition, obesity and diet-related chronic diseases. Globalization Health 2006;2:1-18. DOI: 10.1186/ 1744860324. www.globalizationandhealth. com/content/2/1/4 (accessed 26/01/2009).

- He YN, Zhai FY, Wang ZH, Wang HJ, Hu YS, Yang XG: The status and trend for dietary pattern of energy, protein and fat in Chinese residents. Acta Nutrimenta Sinica 2005;27: 358-365.

Henry J: Processing, manufacturing, uses and labelling of fats in the food supply. Ann Nutr Metab 2009;55:273-300.

- Hu FB, Stampher MJ, Manson JE, Rimm EB, Colditz GA, Rosner BA, Speizer FE, Hennekens $\mathrm{CH}$, Willet WC: Frequent nut consumption and risk of coronary heart disease in women: prospective cohort study. BMJ 1998; 317:1341-1345.

IFFO: The production of fishmeal and fish oil from Peruvian anchovy (data sheet). 2008a. www.iffo.net/intranet/content/archivos/67. pdf.

IFFO: The importance of dietary EPA \& DHA omega-3 fatty acids in the health of both animals and humans. 2008b. www.iffo.net/intranet/content/archivos/75.pdf(accessed 22/ 10/2008).

-Innis SM, Green TJ, Halsey TK: Variability in the trans fatty acid content of foods within a food category: implications for estimation of dietary trans fatty acid intakes. J Am Coll Nutr 1999;18:255-260.

ISSFAL (International Society for the Study of Fatty Acids and Lipids): Recommendations for intake of polyunsaturated fatty acids in healthy adults. 2004. www.issfal.org.uk (accessed 25/07/2008)

Jones RL: Nutritional influences on carcass composition in the broiler chicken. Proc Nutr Soc 1986;45:27-32.

Kandhro A, Sherazi STH, Mahesar SA, Bhanger MI, Talpur MY, Rauf A: GC-MS quantification of fatty acid profile including trans FA in the locally manufactured margarines of Pakistan. Food Chem 2008;109:207-211.

Karabulut I, Turan S: Some properties of margarines and shortenings marketed in Turkey. J Food Compos Anal 2006;19:55-58.

-Khanal RC, Olson KC: Factors affecting conjugated linoleic acid (CLA) content in milk, meat, and egg: a review. Pakistan J Nutr 2004;3:82-98. 
Klensin JC, Feskanich D, Lin V, Truswell S, Southgate DAT: Identification of Food Components for INFOODS Data Interchange. Tokyo, United Nations University, 1989.

-Kris-Etherton PM, Etherton TD: The impact of the changing fatty acid profile of fats on diet assessment and health. J Food Compos Anal 2003; 16:373-378.

Kris-Etherton PM, Yu-Poth S, Sabaté J, Ratcliffe HE, Zhao G, Etherton TD: Nuts and their bioactive constituents: effects on serum lipids and other factors that affect disease risk. Am J Clin Nutr 1999;70(suppl):504S-511S.

- Labadarios D, Steyn NP, Maunder E, MacIntyre U, Gericke G, Swart R, Huskisson J, Dannhauser A, Vorster HH, Nesmvuni AE, Nel JH: The National Food Consumption Survey (NFCS): South Africa, 1999. Public Health Nutr 2005;8:533-543.

Layton L: FDA draft report urges consumption of fish, despite mercury contamination. The Washington Post, 2008. www.washingtonpost.com/wp-dyn/content/article/ 2008/12/11/AR2008121103394_pf.html (accessed 02/06/2009).

- Lee JH, O'Keefe JH, Lavie CJ, Marchioli R, Harris WS: Omega-3 fatty acids for cardioprotection. Mayo Clin Proc 2008;83:324-332.

Lemaitre RN, King IB, Mozaffarian D, Sotoodehnia N, Rea TD, Kuller LH, Tracy RP, Siscovick DS: Plasma phospholipid trans fatty acids, fatal ischemic heart disease, and sudden cardiac death in older adults: the cardiovascular health study. Circulation 2006;114: 209-215.

- MacIntyre UE, Kruger HS, Venter CS, Vorster HH: Dietary intakes of an African population in different stages of transition in the North West Province, South Africa: the THUSA study. Nutr Res 2002;22:239-256.

-Misra A, Sharma R, Pandey RM, Khanna N: Adverse profile of dietary nutrients, anthropometry and lipids in urban slum dwellers of northern India. Eur J Clin Nutr 2001;55:727734.

Mitchell N: Trade in livestock products. Presentation Int Agri Trade Symp, Auckland, 19-20 January 2001. 2001. http://ageconsearch. umn.edu/bitstream/14554/1/cp01mi01.pdf (accessed 03/09/2008).

-Nestle M: Mediterranean diets: historical and research overview. Am J Clin Nutr 1995;61: 1313S-1320S

Nierentz J: Factors influencing fish trade in developing countries: adapting to globalization and outlook for trade. 7th North Pacific Rim Fisheries Conf, Busan, 20 May 2004.

-O’Brien BC, Reiser R: Human plasma lipid responses to red meat, poultry, fish, and eggs. Am J Clin Nutr 1980;33:2573-2580.

-O’Dea K, Traianedes K, Chrisholm K, Leyden H, Sinclair AJ: Cholesterol-lowering effect of a low-fat diet containing lean beef is reversed by the addition of beef fat. Am J Clin Nutr 1990;52:491-494.
OECD-FAO: OECD-FAO agricultural outlook 2008-2017. 2008. www.agri-outlook.org/dataoecd/54/15/40715381.pdf (accessed 10/09/ 2008).

Oh SY, Ryue J, Hsieh C-H, Bell DE: Eggs enriched in $\mathrm{n}-3$ fatty acids and alterations in lipid concentrations in plasma and lipoproteins and blood pressure. Am J Clin Nutr 1991;54:689-695.

Paeratakul S, Ferdinand DP, Champagne CM, Ryan DH, Bray GA: Fast-food consumption among US adults and children: dietary and nutrient intake profile. J Am Diet Assoc 2003;103:1332-1338.

Patton D: Vegetable oil prices set to stay high, US warns. 2008. www.foodnavigator.com/ financial-industry/vegetable-oil-pricesset-to-stay-high-US-warns (accessed on 12/08/2008).

- Piedecausa MA, Mazón MJ, García García B, Hernández MD: Effects of total replacement of fish oil by vegetable oils in the diets of sharpsnout seabream (Diplodus puntazzo). Aquaculture 2007;263:211-219.

- Ponte PIP, Alves SP, Bessa RJB, Ferreira MA, Gama LT, Brás JLA, Fontes CMGA, Prates JAM: Influence of pasture intake on the fatty acid composition, and cholesterol, tocopherol, and tocotrienols content in meat from free-range broilers. Poult Sci 2008;87:8088

Popkin BM: Part II. What is unique about the experience in lower- and middle-income less-industrialised countries compared with the very-high-income industrialised countries? The shift in stages of the nutrition transition in the developing world differs from past experiences? Public Health Nutr 2002;5:205-214.

Popkin BM: Will China's nutrition transition overwhelm its health care system and slow economic growth? Health Affairs 2008;27: 1064-1076.

Popkin BM, Gordon-Larsen P: The nutrition transition: worldwide obesity dynamics and their determinants. Int J Obesity 2004;28 S2-S9.

SAMIC (South African Meat Industry Company): History of meat (not dated). www.samic. co.za/SAMIC/Introduction.htm (accessed 21/08/2008)

Sayed N, Frans Y, Schönfeldt HC: Composition of South African Foods. Milk and milk products, Eggs, Meat and meat products. Supplement to the MRC Food Composition Tables 1991. Cape Town, South African Medical Research Council, 1999.

Schönfeldt HC, Welgemoed C: Composition of South African Beef. Pretoria, South African Meat Board, 1996.

Scollan N: 2003. Strategies for Optimising the Fatty Acid Composition of Beef. IGER Innovations.www.iger.bbsrc.ac.uk/Publica-tions/ Innovations/In2003/Ch7.pdf (accessed 07/ 08/2008).
Scollan N, Hocquette J-F, Nuernberg K, Dannenberger D, Richardson I, Moloney A: Innovations in beef production systems that enhance the nutritional and health value of beef lipids and their relationship with meat quality. Meat Sci 2006;74:17-33.

-Serra-Majem L, MacLean D, Ribas L, Brulé D, Sekula W, Prattala R, Garcia-Closas R, Yngve A, Lalonde M, Petrasovits A: Comparative analysis of nutrition data from national, household, and individual levels: results from a WHO-CINDI collaborative project in Canada, Finland, Poland, and Spain. J Epidemiol Community Health 2003;57:74-80.

Shetty PS: Nutrition transition in India. Public Health Nutr 2002;5:175-182.

-Speedy AW: Global production and consumption of animal source foods. J Nutr 2003;133: 4048S-4053S.

-Stender S, Dyerberg J, Bysted A, Leth T, Astrup A: A trans world journey. Atheroscler Suppl 2006;7:47-52.

Steyn NP, Nel JH: Dietary intake of adult women in South Africa and Nigeria with a focus on the use of spreads. Cape Town, Medical Research Council, 2006, p 89. www.mrc.ac.za/ chronic/kenyareport.pdf (accessed 28/08/ 2008).

Tacon AGJ: Dependence of intensive aquaculture systems on fishmeal and other fishery resources - trends and prospects. FAO Aquaculture Newsletter 6, April 1994. Rome, FAO, 1994, pp 10-16.

- Tarrago-Trani MT, Phillips KM, Lemar LE, Holden JM: New and existing oils and fats used in products with reduced trans-fatty acid content. J Am Diet Assoc 2006; 106:867880.

Thoenes P: Biofuels and commodity markets palm oil focus. FAO, commodities and trade division. 2006. www.rlc.fao.org/es/prioridades/bioenergia/pdf/commodity.pdf (accessed 05/01/2009)

-Ueshima H, Stamler J, Elliott P, Queenie C, Brown IJ, Carnethon MR, Daviglus ML, He K, Moag-Stahlberg A, Rodriguez BL, Steffen LM, van Horn L, Yarnell J, Zhou B: Food omega-3 fatty acid intake of individuals (total, linolenic acid, long-chain) and their blood pressure. INTERMAP Study. Hypertension 2007;50:313-319.

US Census Bureau: Global Population at a Glance: 2002 and Beyond. International brief. March 2004. www.census.gov/ipc/ prod/wp02/wp02-1.pdf (accessed 17/07/ 2008).

USDA: Livestock and poultry: world markets and trade. Circular Series DL\&P1-05. United States Department of Agriculture, 2005, p 1. www.fas.usda.gov/dlp/circular/2005/0504LP/cover.pdf (accessed 03/09/2008).

USDA: USDA National Nutrient Database for Standard Reference (releases 20 and 21; release numbers change as new versions are released): nutrient data laboratory home page. 2007, 2008. http://www.ars.usda.gov/nutrientdata. 
US FDA. Mercury levels in commercial fish and shellfish. 2006. www.cfsan.fda.gov/ frf/seamehg.html (accessed 22/08/2008).

-Van Heerden SM, Schönfeldt HC, Kruger R, Smit MF: The nutrient composition of South African lamb (A2 grade). J Food Compos Anal 2007;20:671-680.

-Wang C, Harris WS, Chung M, Lichtenstein AH, Balk EM, Kupelnick B: n-3 Fatty acids from fish or fish-oil supplements, but not $\alpha$-linolenic acid, benefit cardiovascular disease outcomes in primary- and secondary-prevention studies: a systematic review. Am J Clin Nutr 2006;84:5-17.

WHO/FAO: Diet, nutrition and the prevention of chronic diseases (report of a joint $\mathrm{WHO} /$ FAO Expert Consultation). WHO Technical Report Series 916. Geneva, WHO, 2003, p 146.
Wikipedia: Olive oil. http:en.wikipedia.org/wiki/ Olive_oil (accessed 08/06/2009).

-Wolmarans P, Langenhoven ML, van Eck M, Swanepoel ASP: The contribution of different food groups to the energy, fat and fibre intake of the Coronary Risk Factor Study (CORIS) population. S Afr Med J 1989;75 167-171.

-Wolmarans P, Laubscher JA, van der Merwe S, Kriek JA, Lombard CJ, Marais M, Vorster HH, Tichelaar HY, Dhansay A, Benadé AJS: Effects of a prudent diet containing either lean beef and mutton or fish and skinless chicken on the plasma lipoproteins and fatty acid composition of triacylglycerol and cholesterol ester of hypecholesterolemic subjects. J Nutr Biochem 1999;10:598-608.
-Wood JD, Enser M, Fisher AV, Nute GR, Sheard PR, Richardson RI, Hughes SI, Whittington FM: Fat deposition, fatty acid composition and meat quality: a review. Meat Sci 2008;78: 343-358.

-Wright JD, Kennedy-Stephenson J, Wang CY, McDowell MA, Johnson CL: Trends in intake of energy and macronutrients - United States, 1971-2000. MMWR 2004;53:80-82.

Zhai FY, Ge KY, Jin SG: Summary report of China Health and Nutrition Survey. J Hyg Res 1996;22:16-25.

Zlatanos S, Laskaridis K: Seasonal variation in the fatty acid composition of three Mediterranean fish - sardine (Sardina pilchardus), anchovy (Engraulis encrasicholus) and picarel (Spicara smaris). Food Chem 2007;103: 725-728. 